\title{
Brain Derived Exosomes Are a Double-Edged Sword in Alzheimer's Disease
}

\section{Zhiqi Song, Yanfeng Xu, Wei Deng, Ling Zhang, Hua Zhu, Pin Yu, Yajin Qu, Wenjie Zhao, Yunlin Han and Chuan Qin*}

Key Laboratory of Human Disease Comparative Medicine, Chinese Ministry of Health, Beijing Key Laboratory for Animal Models of Emerging and Remerging Infectious Diseases, Institute of Laboratory Animal Sciences, Chinese Academy of Medical Sciences, Comparative Medicine Center, Peking Union Medical College, Beijing, China

Brain derived exosomes (BDEs) are extracellular nanovesicles that are collectively released by all cell lineages of the central nervous system and contain cargo from their original cells. They are emerging as key mediators of communication and waste management among neurons, glial cells and connective tissue during both physiological and pathological conditions in the brain. We review the rapidly growing frontier of BDEs biology in recent years including the involvement of exosomes in neuronal development, maintenance and communication through their multiple signaling functions. Particularly, we highlight the important role of exosomes in Alzheimer's disease (AD), both as a pathogenic agent and as a disease biomarker. Our understanding of such unique

OPEN ACCESS

Edited by:

Michele Papa,

University of Campania Luigi Vanvitelli,

Italy

Reviewed by:

Ursula Wyneken,

University of the Andes, Chile, Chile

Minho Moon,

Konyang University, South Korea Esperanza González, CIC bioGUNE, Spain

${ }^{*}$ Correspondence:

Chuan Qin

qinchuan@pumc.edu.cn

Received: 17 March 2020

Accepted: 22 April 2020

Published: 29 May 2020

Citation:

Song Z, XU Y, Deng W, Zhang L,

Zhu H, Yu P, Qu Y, Zhao W, Han Y and Qin C (2020) Brain Derived Exosomes Are a Double-Edged

Sword in Alzheimer's Disease.

Front. Mol. Neurosci. 13:79. doi: 10.3389/fnmol.2020.00079 nanovesicles may offer not only answers about the (patho) physiological course in AD and associated neurodegenerative diseases but also ideal methods to develop these vesicles as vehicles for drug delivery or as tools to monitor brain diseases in a noninvasive manner because crossing the blood brain barrier is an inherent capability of exosomes. BDEs have potential as biomarkers and as therapeutic tools for AD and related brain disorders in the near future.

Keywords: brain derived exosomes, Alzheimer's disease, cell-to-cell communication, biomarker, extracellular vesicles

Abbreviations: $\alpha$-SYN, $\alpha$-synuclein; $A \beta$, amyloid $\beta$-protein; AD, Alzheimer's disease; ALIX, ALG-2-interacting protein X; AMPA, $\alpha$-amino-3-hydroxy-5-methyl-4-isoxazolepropionic acid; Apo-E, apolipoprotein E; APP, amyloid precursor protein; ARF6, ADP ribosylation factor 6;BACE1, beta-secretase 1; BBB, blood brain barrier; BDNF, brain derived neurotrophic factor; BDEs, brain derived exosomes; BIN1, Bridging I Ntegrator 1; cAMP, cyclic adenosine monophosphate; CD, Cluster of differentiation; CNS, central nervous system; CREB1, cAMP responsive element binding protein 1; CSF, cerebrospinal fluid; CT, computed tomography; ESCRT, the endosomal sorting complex required for transport; ECG, Electrocardiography; EE, early endosome; EGFR, epidermal growth factor receptor; EVs, extracellular vesicles; gDNA, genomic DNA; GAP43, growth associated protein 43; HSP, heat shock protein; IRS1, insulin receptor substrate 1; Ibal, ionized calcium-binding adapter molecule 1; IGF1, insulin-like growth factor 1; IL-1 $\beta$, interleukin 1 beta; ILVs, intraluminal vesicles; LE, late endosome; L1CAM, neuronal L1 cell adhesion molecule; LRP6, LDL receptor related protein; MCI, mild cognitive impairment; miRNA, micro ribonucleic acid; MMPs, matrix metalloproteinase regulators; MRI, magnetic resonance imaging; mRNA, messenger ribonucleic acid; MS, multiple sclerosis; MSCs, mesenchymal stromal cells; MVBs, multivesicular bodies; MVEs, multivesicular endosomes; Neuro-2a, Murine neuroblastoma; nSMase2, neutral sphingomyelinase-2; NSCs, neural stem cells; NTA, nanoparticle tracking analysis; PD, Parkinson's disease; PrP, prion protein; p-S396-tau, Tau phosphorylation at serine 396; p-T181-tau, Tau phosphorylation at threonine 181; qPCR real-time quantitative polymerase chain reaction; REST, re1 silencing transcription factor; S1P, sphingosine-1-phosphate; S1PR, S1P receptor; siRNA, small interfering ribonucleic acid; SMS2, sphingomyelin synthase 2; sMVBs, secretory multivesicular bodies; TGF $\beta$, transforming growth factor beta; TSG101, tumor susceptibility gene 101 protein. 


\section{INTRODUCTION}

Exosomes are small extracellular nano-sized vesicles between 30 and $150 \mathrm{~nm}$ in diameter (DeLeo and Ikezu, 2018) that were first described in the 1980s (Johnstone et al., 1987). They consist of one type of EVs and are categorized on the basis of their biogenesis pathways (Pan and Johnstone, 1983). Since then, exosomes have been isolated from nearly all mammalian cell types, including cells in the CNS such as neurons, astrocytes, oligodendrocytes, microglia, and Schwann cells, as well as endothelial cells (Faure et al., 2006; Sharma et al., 2013). Exosomes released from the nervous system are collectively called BDEs.

To form MVBs with ILVs, early endosomes undergo inward budding (Colombo et al., 2014). Then, ILVs are released into the extracellular environment as exosomes via fusion of MVBs with the plasma membrane (Heijnen et al., 1999; Mulcahy et al., 2014). Alternatively, exosomal formation can be regulated by sphingolipids, ceramides and tetraspanins (Trajkovic et al., 2008; Stuffers et al., 2009; van Niel et al., 2011). Otherwise, MVBs can fuse with the lysosomal membrane, resulting in degradation of ILVs and recycling of their content (Stuffers et al., 2009; Klumperman and Raposo, 2014). As a result of their origin and multifarious molecular cargo, including but not limited to gDNA, mRNA, other non-coding RNAs, lipids and proteins (Yokoi et al., 2019), the molecular species and relative amounts in exosomes are highly heterogeneous and complex in composition. Exosomes can randomly or selectively exhibit great variety depending on their membranes, cytosolic proteins, and nucleic acids compared with the cells that release them. Based on the proteomic and other comprehensive analyses, the heterogeneity of exosomes is conceptualized on the basis of their size, content (cargo), functional impact on recipient cells and cell of origin (source) (Kalluri and LeBleu, 2020). It is becoming increasingly clear that exosomes have specialized functions and play a key role in coagulation, intercellular signaling and waste management (van der Pol et al., 2012; Figure 1).

During the formation process, exosomes are comprised of enriched endosome-associated components such as flotillins and annexins (van Niel et al., 2006), ALIX, the ESCRT component, tumor susceptibility gene 101 protein (TSG101) (Lotvall et al., 2014) and lipid rafts, including cholesterol, sphingomyelin and ceramide (DeLeo and Ikezu, 2018). Moreover, membrane proteins, including tetraspanins such as abundant CD9, CD63, and CD81, that are considered as markers for exosomes and play important roles in the biogenesis of endosomes or MVBs (Lotvall et al., 2014; Kowal et al., 2016). Depending on the cell type from which they are secreted, exosome vesicles themselves also hold particular and varied types of markers that contribute to identifying their origins (Lotvall et al., 2014; Kowal et al., 2016). For example, neuronal L1 cell adhesion molecule (L1CAM) can be used as a biomarker for isolating BDEs (Cicognola et al., 2019).

Once the exosomes are secreted, they can be internalized from the extracellular space by recipient cells through several mechanisms including phagocytosis, micropinocytosis, endocytosis, and plasma membrane fusion (McKelvey et al., 2015; Figure 1). On the other hand, exosomes carrying multiple cargo with valuable biological information can also be released into most bodily fluids such as plasma, cerebrospinal fluid, urine, saliva, amniotic fluid, colostrum, breast milk, synovial fluid, semen and pleural ascites, not only in normal tissues (Corrado et al., 2013; McKelvey et al., 2015) but also in aberrant bodies such as tumors (Camussi et al., 2011; Rak and Guha, 2012). For the above reasons, exosomes play key roles in the management of normal physiological environments, such as immune surveillance (Rajendran et al., 2006), stem cell maintenance (Ratajczak et al., 2006), tissue repair (Gatti et al., 2011), and blood coagulation (Del et al., 2005), as well as in the pathological processes associated with several diseases (Liu et al., 2019), including neurodegenerative diseases such as AD (Bellingham et al., 2012; Watson et al., 2019) and PD (Emmanouilidou et al., 2010).

Given the characteristic described above, exosomes and their constituents represent a novel class of therapeutic targets and such features also give them advantages as biomarkers to distinguish healthy and disease states (Emmanouilidou et al., 2010) and for prognosis prediction and therapy for diseases. Moreover, recent studies have demonstrated that exosomes may also be directly considered as potential therapeutic agents. For instance, mesenchymal stem cell-derived exosomes have been used in tissue regeneration (Lai et al., 2011; Timmers et al., 2011) and tumor antigen-pulsed dendritic cell-derived exosomes have been developed for cancer immune response modulation (Zitvogel et al., 1998). Remarkably, exosomes have an efficient capability to cross the BBB (Chen et al., 2016). In particular, exosomes isolated from CSF are rich in proteins that originate from the brain such as neuron-specific markers, microglial markers (CD11b and CD45) and Apo-E (Chiasserini et al., 2014), making them potential novel drug delivery vehicles for treating nervous system diseases. Here, we mainly discuss and summarize the role of BDEs in normal biological processes in the CNS as well as the aberrant pathological state of $\mathrm{AD}$ and focus on explaining how exosomes can be targeted or directly exploited as biomarkers or therapeutics in $\mathrm{AD}$.

\section{PHYSIOLOGICAL ROLES OF BDES IN THE CNS}

Exosomes exert their effects on essential biological processes throughout the body including the CNS by different mechanisms. These mechanisms include cell surface receptors activation through direct binding to lipid ligands and proteins, exosomal membrane fusion contents with the recipient cell plasma membrane and effectors delivery. Some of these effectors are oncogenes, transcription factors, small and large non-coding regulatory RNAs (such as miRNAs) and mRNAs, as well as infectious particles such as amyloid- $\beta(\mathrm{A} \beta)$-derived (Bellingham et al., 2012) and $\alpha$-synuclein (Emmanouilidou et al., 2010) into recipient cells (Camussi et al., 2011; Lee et al., 2012; Figure 1). In this manner, exosomes participate in the maintenance of normal physiology (Figure 2).

Particularly, in the CNS, exosomes can be released from virtually all cell types, including various types of neurons, 


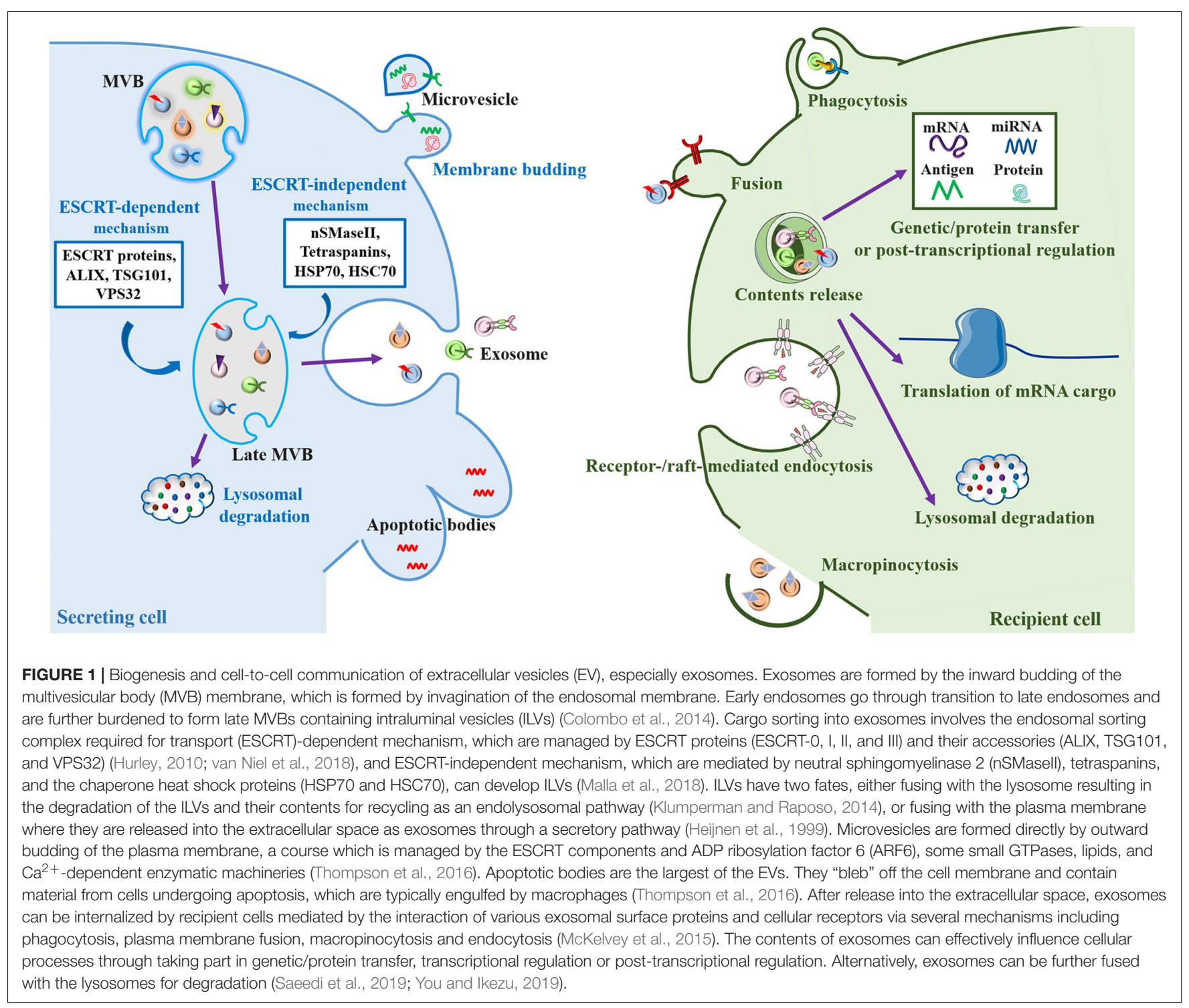

astrocytes, oligodendrocytes, microglia, and Schwann cells, as well as endothelial cells (Faure et al., 2006; Sharma et al., 2013). EVs carry and release multiple molecules related to neuronal function and neurotransmission in the brain, which is beneficial for the reciprocal communication between neural cells (e.g., neuron-glia interactions), synaptic plasticity, neuronal development, and neuroimmune communication (Fruhbeis et al., 2013a; Rajendran et al., 2014; Iraci et al., 2016; Table 1).

\section{Neuron-Glia Communication via Exosome Secretion}

Neurons and glial cells (a class of cells that mainly includes microglia, astrocytes, and oligodendrocytes) orchestrate CNS homeostasis via numerous mechanisms of intercellular communication. Exosomes might regulate the physiological condition of the recipient cells and interactions between various neural cells. For example, upon activation of glutamatergic synapses, cortical neuron-derived exosomes are selectively delivered to neurons but not glial cells (Koniusz et al., 2016). Recent studies using CD63-GFP positive intraluminal vesicles as exosomal reporter in mice have demonstrated that exosomes participate in mediating neuron to astroglia communication in the CNS (Men et al., 2019). Furthermore, miRNAs (especially miR-124a) in exosomes isolated from neuron-conditioned medium possess excitatory amino acid transporter 2, a necessary mediator of glutamate uptake via the internalization of exosomes into astrocytes (Morel et al., 2013). However, exosomes also participate in reciprocal oligodendrocyte-neuron communication and transfer cargo from oligodendrocytes to neurons (Fruhbeis et al., 2013a). Although exosome-mediated communication and the manner by which exosomes select their recipient cells are largely unclear, emerging evidence suggests that exosomes serve as selectively important conveyers for neuronneuron or neuron-glia interaction in the brain by transmitting genetic information, various bioactive proteins, and lipids. 


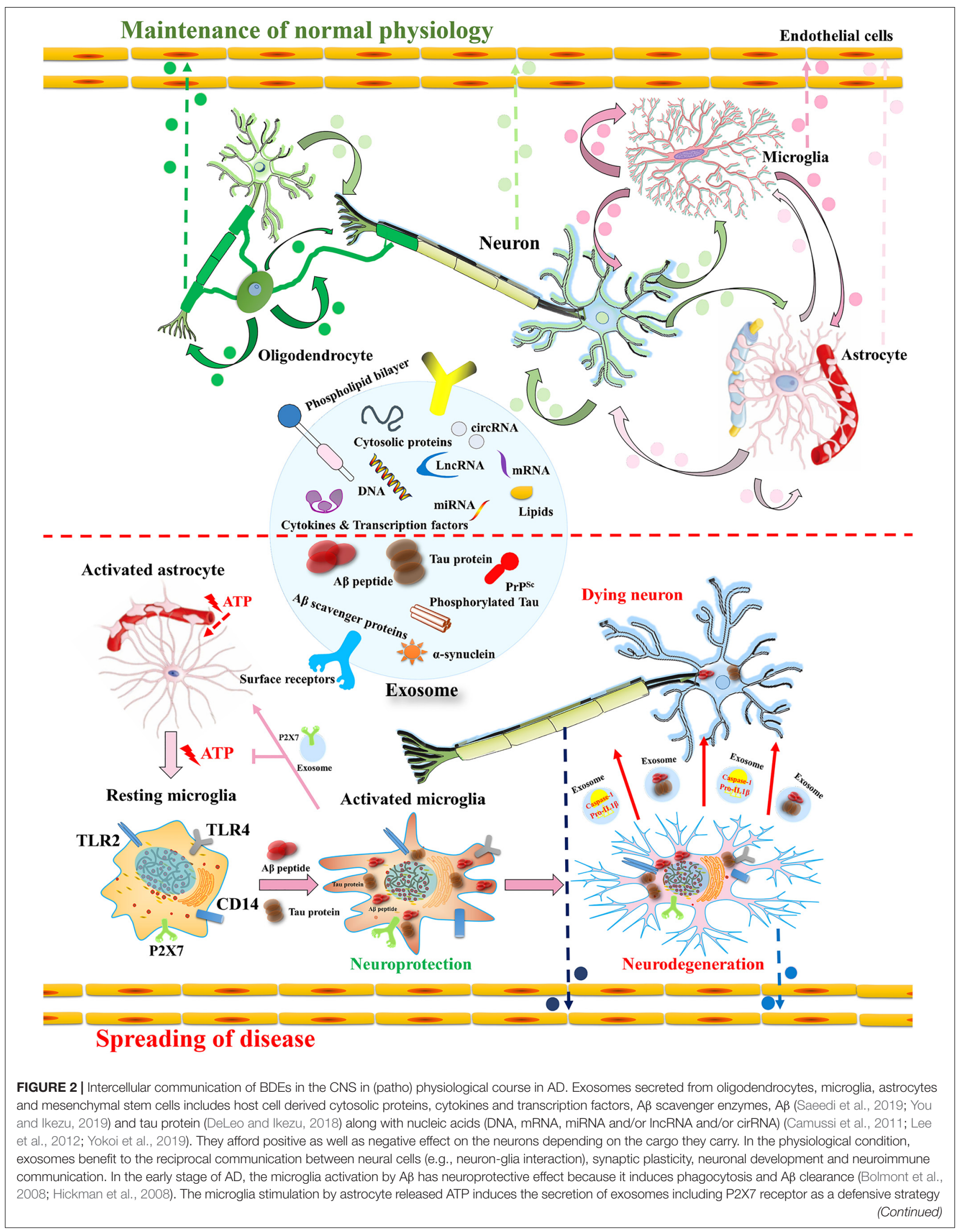




\section{FIGURE 2 | Continued}

to escape astrocyte signaling (Bolmont et al., 2008; Hickman et al., 2008). In the latter stage of AD, microglia secrete exosomes containing pro-IL1 $\beta$, active caspase-1 and soluble toxic A $\beta$ that have detrimental effects on neurons (Bianco et al., 2005; Trotta et al., 2018). Neurodegenerative associated proteins such as A $\beta$, Tau, prions (Faure et al., 2006) and $\alpha$-synuclein (Emmanouilidou et al., 2010) can also be derived from neural derived exosomes, leading to the spread of protein aggregate seeds and disease progression. In addition, these exosomes could be exported via blood-brain barrier as circulatory EVs, which can be used for disease-specific biomarkers, even future for therapeutic researches (Thompson et al., 2016).

TABLE 1 | Exosome is a double-edged sword in nervous system.

\begin{tabular}{|c|c|c|c|}
\hline Condition & \multicolumn{2}{|c|}{ Function } & \multirow{2}{*}{$\begin{array}{l}\text { References } \\
\text { Fruhbeis et al., 2013b }\end{array}$} \\
\hline Physiological roles & Neuron-glia communication & Neuron and microglia & \\
\hline & & Neuron and astrocytes & Men et al., 2019; Pascua-Maestro et al., 2019 \\
\hline & & Neuron and oligodendrocytes & Kramer-Albers et al., 2007 \\
\hline \multirow[t]{8}{*}{ Pathological roles in AD } & Synaptic & d neurotransmission & Chivet et al., 2012; Koniusz et al., 2016 \\
\hline & Enhar & euron protection & Guitart et al., 2016 \\
\hline & Impro & onal development & Drago et al., 2017 \\
\hline & Carry the two hallmarks & $A \beta$, and hyperphosphorylated tau & Sardar et al., 2018 \\
\hline & The spre & ers and neurotoxicity & Hamlett et al., 2018 \\
\hline & & aptic proteins & Goetzl et al., 2016a \\
\hline & Carry the ceram & ngosine-1-phosphate (S1P) & Yuyama et al., 2012; Dinkins et al., 2014 \\
\hline & Containing tyrosine phc & insulin receptor substrate 1 (IRS1) & Kapogiannis et al., 2015 \\
\hline
\end{tabular}

\section{Synaptic Plasticity and Neurotransmission by the Release of Exosomes}

Maintenance and improvement of synaptic connectivity in the adult brain are crucial for cognitive function. Neural synaptic plasticity is mediated not only by neuron-specific progression but also by glial cells, such as astrocytes and microglia (Morris et al., 2013). Under resting conditions, synaptic vesicles are reposited in the cytoplasm of the nerve terminal. Many synaptic vesicles stick on some specialized sites at the presynaptic plasma membrane named active zones. During incoming action potentials, exocytosis of synaptic vesicles confirm how much transmitter is released from nerve terminals (Jahn and Fasshauer, 2012). In addition to typical synaptic neurotransmission, signal transduction of neurons via the secretion of exosomes can induce a range of neurobiological functions including synaptic plasticity (Chivet et al., 2012; Koniusz et al., 2016). During management of synaptic plasticity, PC12 cell-derived exosomes can stimulate synaptic pruning through enhancement of the complement component 3 level in microglial MG6 cells (Bahrini et al., 2015). For instance, enhanced secretion of cortical neuronderived exosomes containing neurotransmitter receptors leads to increased glutamatergic activity (Lachenal et al., 2011). Additionally, by managing the number of AMPA receptors for glutamate transmission, neuronal-derived exosomes might affect synaptic plasticity (Lachenal et al., 2011).

\section{Enhancement of Neuron Protection and Neuronal Development Through Exosomes}

Although the understanding of astrocyte-neuron communication via exosomes remains unclear, evidence supports that it does occur, and this communication manner is required for neuronal cell survival (Figure 2; Pascua-Maestro et al., 2019; Luarte et al., 2020). Neuroprotective signaling is essential for neuronal growth and survival. $\operatorname{PrP}$ is a physiologically important receptor protein that protects against oxidative stress in the CNS. Protection of neurons through astrocyte-derived exosomes is dependent on astrocyte-derived exosomal PrP transport into neurons (Guitart et al., 2016). In addition, studies have demonstrated that microglia and oligodendrocytederived exosomes contribute to neuronal energy metabolism by transferring several enzymes involved in energy metabolism (Kramer-Albers et al., 2007; Drago et al., 2017). Thus, exosomes mediate several vital processes involved in normal brain function. Taken together, these findings suggest that exosome-mediated cell communication is emerging as a method of mediating neuron protection.

\section{PATHOLOGICAL ROLES OF BDES IN AD}

Increased secretion of exosomes is generally thought to occur in response to stress or pathological conditions (Urbanelli et al., 2013; Saxton and Sabatini, 2017; Gill et al., 2018), such as hypoxia (King et al., 2012; Ophelders et al., 2016), alcoholism (Momen-Heravi et al., 2015), cisplatin- (Xiao et al., 2014), or irradiation-induced DNA damage (Lehmann et al., 2008), and oxidative stress (Atienzar-Aroca et al., 2016). Neuron-derived exosomes including particular proteins associated with neurodegenerative diseases can be secreted from the affected neurons (Watson et al., 2019). In the case of $\mathrm{AD}$, there are two hallmarks of $\mathrm{AD}$ brains, $\mathrm{A} \beta$ and hyperphosphorylated tau, interact with specific endosomes and may contribute to exosome biogenesis in AD (Sardar et al., 2018). Additionally, exosomal proteins, such as flotillin-1 and Alix, were observed to accumulate around amyloid plaques in $\mathrm{AD}$ patients 
(Rajendran et al., 2006). The formation, secretion or uptake of exosomes plays a dual role in the spread of oligomers and neurotoxicity (Table 1).

\section{Exosomes Containing $A \beta$ in AD}

Amyloid $\beta$-protein is a C-terminal cleavage product of the transmembrane APP produced by $\beta$ - and $\gamma$-secretase (Devi and Anandatheerthavarada, 2010; Miranda et al., 2018). AD is characterized by the presence of aggregates of pathologically misfolded proteins in the brain, including extracellular senile plaques mainly consisting of A $\beta$ (Brunkhorst et al., 2014). Numerous reports have described these proteins and their substrates within exosomes of in vitro $\mathrm{AD}$ models and in exosomes derived from neurons of AD patients (Dinkins et al., 2014; Yuyama et al., 2015).

Although most $\mathrm{AD}$ cases are sporadic, there is a minority patients from mutations in the genes encoding APP or during sequential cleavages by $\beta$ - and $\gamma$-secretase enzyme activities (Chow et al., 2010). In vitro, exosomes isolated from neuronal cell lines show that inducing AD mutations can increase sAPP protein $\beta, \operatorname{sAPP} \alpha$ (Xiao et al., 2017; Sinha et al., 2018) and soluble A $\beta 1-42$ (Eitan et al., 2016a). N2a cells expressing human APP with the autosomal dominant Swedish mutation contain A $\beta$ peptides as well as the C-terminal fragments of APP have also shown increase of production of C-end terminal fragments (a byproduct of APP after $\beta$-secretase processing) (Laulagnier et al., 2018), $\beta$-secretase in released exosomes, and co-localization of $\beta$-secretase enzyme 1 with early exosome markers (Xiao et al., 2017). Vesicles released by A $\beta$-treated astrocytes contain the proapoptotic prostate apoptosis response 4 (PAR-4) protein and these vesicles cause PAR-4 associated apoptosis in naive cultures (Wang et al., 2012). Experiments involving the medium of neural cells expressing familial $\mathrm{AD}$ presenilin 1 mutations show that $\mathrm{A} \beta$ is associated with exosomes during their excretion process (Eitan et al., 2016b).

In vivo, rodent exosomes can contain $\mathrm{A} \beta$, BACE1, and presenilin 1 and 2 (Sharples et al., 2008). Exosomes isolated from bodily fluids of AD mouse model, including blood, CSF and urine, display indicative increase in the C-terminal fragments of APP (Laulagnier et al., 2018; Miranda et al., 2018). Exosomes isolated from bodily fluids of $\mathrm{AD}$ patients exhibit a remarkable increase soluble A $\beta 1-42$ in Abner et al. (2016); Winston et al. (2016), Hamlett et al. (2017, 2018). Amyloid plaques in AD brains also contain an exosome marker (Abner et al., 2016; Winston et al., 2016; Hamlett et al., 2017, 2018). The muskelin protein is involved in reorganization of the cytoskeleton and has been shown to be involved in the determination of either lysosomal degradation or exosome secretion of PrP (Heisler et al., 2018). Importantly, $\mathrm{PrP}$ is a receptor for $\mathrm{A} \beta$ and is reported to increase the pathogenicity of $\mathrm{AD}$ (Cohen et al., 2016). Muskelin may play a critical role in this type of amyloidosis.

The above data suggested the hypothesis that exosomes could seed $A \beta$ aggregation (Dinkins et al., 2017). However, neuronal exosomes can also restrain $A \beta$ oligomerization and accelerate $\mathrm{A} \beta$ fibril formation, facilitating microglia-mediated $\mathrm{A} \beta$ clearance in vitro (Yuyama et al., 2012). Moreover, in an AD mouse model, intracerebral loading of glycosphingolipid-enriched exosomes led to trapping and transporting $A \beta$ into microglia, leading to a decrease in $A \beta$ pathology (Yuyama et al., 2014). These results might explain why, at least under some circumstances, exosomes associated with $\mathrm{A} \beta$ have a physiological, neuroprotective function (Yuyama and Igarashi, 2017). It is also possible that in the brain as exosomes are secreted by various cell types (e.g., neurons, microglia, and astrocytes), they might exhibit contrary effects or the exosomal membranes might promote $A \beta$ aggregation independent of protein-associated exosomal functions (e.g., $\mathrm{A} \beta$ degradation by exosomal insulin-degrading neprilysin or enzymes) (reviewed in Dinkins et al., 2017).

\section{Exosomes Containing Hyperphosphorylated Tau in AD}

The gradual deposition of hyperphosphorylated tau protein within specific neurons is pivotal to the tauopathy of $\mathrm{AD}$ (Saman et al., 2014; Takeda, 2019). Under normal physiological conditions, incorporation of neuronal microtubule-associated protein tau for microtubule elongation is a crucial event of neuronal synapse formation and synaptic plasticity. Additionally, intracellular tau also participates in neurite outgrowth, axonal transport, chromosome stability, regulation the cellular transcriptome and the structural architecture of heterochromatin (for more details see the review by Sotiropoulos et al., 2017). Extracellular tau is also secreted into brain interstitial fluid (Yamada et al., 2011) and may contribute to some characteristics of sleep (Lucey et al., 2019). The above functions rely on the site-specific phosphorylation of tau (Kapitein and Hoogenraad, 2015) in normal condition. However, hyperphosphorylation and aggregation of the microtubuleassociated tau protein into intracellular neurofibrillary tangles is one of the classical pathological hallmarks of advanced-stage AD (Johnson and Stoothoff, 2004; Martin et al., 2011).

During the progressive accumulation of neurofibrillary tangles, tau becomes hyperphosphorylated in neurons. Meanwhile, the cellular clearance machinery takes up tau for degradation and packaging in exosomes (Saman et al., 2012; Chesser et al., 2013; Perez et al., 2019). In an adeno-associated virus-based mouse model revealing rapid tau propagation, microglia help to spread tau through exosome release, and depletion of microglia or inhibition of exosome synthesis significantly decreases the propagation of tau in vitro and in vivo (Asai et al., 2015). In another mouse model of tauopathy, aggregated tau was isolated from and transmitted through brain exosomes (Asai et al., 2015). In these mice, exosomes that were isolated from the brains of tau transgenic rTg4510 mice containing human four-repeat tau with the P301L mutation accelerated pathological tau phosphorylation and oligomer formation (Polanco et al., 2016), indicating that neuronal exosomes containing human mutated tau are toxic to the recipient neurons in vivo (Baker et al., 2016). Recently, BIN1 was found to support spreading of tau via exosome release in mice. Tau-containing exosomes isolated from the CSF of AD-affected individuals who contain BIN1-associated genetic variants in AD etiology showed seeding competence (Crotti et al., 2019). In human patients, compared with BDEs obtained from the plasma 
or serum of age-matched controls, BDEs from $\mathrm{AD}$ patients showed a 3-20-fold increase in tau phosphorylation at threonine 181 (p-T181-tau) and serine 396 (p-S396-tau) (Crotti et al., 2019). Moreover, compared with AD patients who had only been diagnosed with mild cognitive impairment, p-T181-tau levels were significantly higher in BDEs isolated from the plasma of later-stage $\mathrm{AD}$ patients (Winston et al., 2016), demonstrating either a dysfunction of the clearance ability or an increase in pathogenicity of exosomes in later disease states of AD. p-T181and p-S396-tau were significantly decreased in BDEs of patients 1-10 years prior to their AD diagnosis (Fiandaca et al., 2015).

\section{Exosomes Containing Synaptic Proteins in $A D$}

One consequence of $\mathrm{AD}$ is neuron loss and dysfunction. The levels of synaptic proteins, including synaptophysin, synaptotagmins, synaptobrevin, synaptopodin, Rab3A, GAP 43, and neurogranin, were decreased in the BDE cargo from the plasma of AD patients (Goetzl et al., 2016b). Additionally, lowdensity LRP 6, REST, heat shock factor protein 1, HSP, and AMPA receptor levels are also lower in BDEs from the plasma of AD patients (Goetzl et al., 2015, 2016b; Winston et al., 2016). Furthermore, neurexin $2 \alpha$, GluA4-containing glutamate receptor, and neuroligin 1 , essential proteins for long-term potentiation processes, were all significantly reduced in BDEs from the plasma of patients 6-11 years prior to $\mathrm{AD}$ diagnosis and, along with neuronal pentraxin 2, were all downregulated in BDEs (Goetzl et al., 2018, 2019). These proteins are all involved in normal homeostasis of neurons. Further research into these proteins in BDEs could be beneficial for the search for earlier biomarkers of $\mathrm{AD}$.

\section{Ceramide and Sphingosine-1-Phosphate (S1P) in Exosomes in AD}

Activated sphingolipids are signaling molecules that serve as intracellular second messengers and include ceramide, sphingosine, and their derivatives, 1-phosphates (C1P and S1P, respectively) (Czubowicz et al., 2019). Exosomes are sphingomyelin- and ceramide-enriched vesicles formed inside MVEs and then are secreted when the MVE membrane fuses with the plasmalemma. Exosomes can serve as a vehicle for the extracellular secretion and cell-to-cell transport of $A \beta, \alpha-$ synuclein and tau protein, possibly further facilitating the spread of toxic protein aggregation (Ngolab et al., 2017; Wang et al., 2017). S1P receptor (S1PR) signaling has been reported to participate in exosomal cargo sorting. Activity of the S1PRmediated Rho family of GTPases is essential for this process and G $\beta \gamma$ inhibitors inhibit this activity (Kajimoto et al., 2018). The secretion of exosomes can be regulated by the activation of neutral sphingomyelin synthase 2 (SMS2) and sphingomyelinase 2 (nSMase2), demonstrating distinct functions for these enzymes in AD (Yuyama et al., 2012; Dinkins et al., 2014). Additionally, ceramide/sphingolipid shortage results in enhanced secretion of $\operatorname{sA} \beta \mathrm{PP} \alpha$, the product of non-amyloidogenic cleavage. However, this shortage gives rise to increased secretion of $\mathrm{A} \beta 42$ at the same time, probably via regulation of raft-associated proteins, resulting in alteration of the $\alpha$ - vs. $\beta$-cleavage ratio (Yuyama et al., 2012; Dinkins et al., 2014). Enhanced endogenous ceramide and exogenous additional ceramide both elevate the $\mathrm{A} \beta$ level (Puglielli et al., 2003; Sawamura et al., 2004). The above research suggests the significance of the ceramide/sphingolipid levels in the process of $\mathrm{AD}$.

\section{Exosomes Containing Other AD-Associated Proteins}

Dysregulation of insulin by the CNS and peripheral hyperinsulinemia have been reported as other events highly associated with AD (de la Monte, 2009; de la Monte and Tong, 2014; Kim et al., 2015). A low tyrosine phosphorylated insulin receptor substrate 1 (IRS1) to serine phosphorylated IRS1 ratio is a characteristic of insulin dysregulation (Aguirre et al., 2002; Draznin, 2006) and is related to greater brain atrophy in AD patients (Mullins et al., 2017). BDEs isolated from the plasma of human $\mathrm{AD}$ patients have revealed an enhancement in serine phosphorylation in IRS1 (Kapogiannis et al., 2015). This study demonstrated that significant differences in the IRS1 levels were recognizable up to 10 years prior to clinical onset of $\mathrm{AD}$, which suggests that proteins within BDEs that are involved in insulin disruption may potentially be useful biomarkers for clinical diagnosis.

Moreover, exosomes have the ability to spread toxic proteins through PrP activity (Hartmann et al., 2017). PrP is a cell surface-anchored protein that is highly related to AD pathology (Kellett and Hooper, 2009). Its pathological, misfolded form is associated with spongiform encephalopathy (Prusiner, 1982; Song et al., 2013). Studies in animal models of AD have demonstrated that the $\operatorname{PrP}$ receptor is essential for the cognitive impairment linked to $\mathrm{A} \beta$ (Gimbel et al., 2010). Additionally, growing evidence indicates that prion receptor on exosomes are capable of transmitting pathological substances (Fevrier et al., 2004; Hartmann et al., 2017). Aberrant autophagy is likely to play a role in this process (Abdulrahman et al., 2018). However, further research is needed to explore the potential mechanism connecting exosomes, $\mathrm{AD}$ pathogenesis, and autophagy.

\section{EXOSOMAL MIRNA AS A DIAGNOSTIC BIOMARKER FOR AD}

Generally, the biomarkers used for $\mathrm{AD}$ diagnosis include the expression of A $\beta$ and pTau (Abdulrahman et al., 2018), and methods such as neuropsychological testing and specialized brain imaging techniques have also been widely used for diagnosis of AD. Unfortunately, most AD patients are asymptomatic during the pre-clinical stages, which may last up to 17 years or longer (Villemagne et al., 2013). Therefore, it is important to exploit early diagnostics to confirm and treat individuals who are at risk before severe and irreversible neuronal pathology occurs.

MiRNAs are a family of 18-22 nt single-stranded RNAs that post-translationally communicate with and regulate the expression of mature mRNAs. Single upregulated miRNAs can target various mRNAs to decrease their expression and multiple miRNAs can target a single mRNA (Sethi and Lukiw, 2009; 
Sarkar et al., 2016). Studies have demonstrated that mRNA and miRNA species are present in exosomes. It is possible that some mRNA sequences are definitely targeted for secretion by these vesicles (Valadi et al., 2007; Van Giau and An, 2016). Exosomal miRNAs play essential roles in intercellular communication between cell membranes in the CNS and in disease progression. Exosomal miRNAs are also ideal targets for use as potential biomarkers in clinical diagnostics or therapies as they can be analyzed through neuronal exosomes in the patient's body fluids (A). Indeed, some research has illustrated that proteins and miRNAs can be transferred from glia to axons (Skog et al., 2008). It is assumed that miRNA signaling can impact neurodegenerative diseases via the dysregulation of tau, leading to neurotoxicity. One study convincingly demonstrated that, in brain tissues obtained at autopsy from $\mathrm{AD}$ patients and from those with severe primary age-related tau pathology, the level of the highly conserved miRNA-219 was decreased in the brain (Santa-Maria et al., 2015). Several reports have illustrated that high expression of tissue-specific miRNAs in the brain, such as miR-9, miR-29a/b, miR-107, miR-124, miR-128, miR-134, and miR-137, may result in defective neuronal development (Sempere et al., 2004; Kawase Koga et al., 2009; Huang et al., 2010). In addition, other miRNAs are also abnormal in brain tissues during neurodegenerative processes. These specific miRNAs, including miR-132 and miR-212, are among the most robustly declining miRNAs in neurodegenerative diseases, including AD (Cogswell et al., 2008; Hebert et al., 2013; Wong et al., 2013; Lau et al., 2014), Huntington's disease (Johnson et al., 2008; Packer et al., 2008), PD (Burgos et al., 2014), schizophrenia and bipolar disorders (Perkins et al., 2007; Kim et al., 2010) and frontotemporal dementia (Chen-Plotkin et al., 2012; Hebert et al., 2013).

Remarkably, miRNAs that were found to be greatly expressed in the brain were also detected in human body fluids such as the plasma, urine, and CSF. The levels of brain-enriched miRNAs including miR-9, miR-29a, miR-29b, and miR-137 have been found to be significantly decreased in plasma samples collected from AD patients (Geekiyanage et al., 2012). Both miR-128 and miR-134 were also examined in patients with mild cognitive impairment, which is an early stage of AD (Sheinerman et al., 2012). These miRNA biomarkers in the blood represents a clinical advantage for early disease diagnosis, but differential miRNA expression may not accurately rescue abnormal miRNA expression in the brain. The CSF represents a more relevant and suitable source for the diagnosis of CNS disorders such as AD (Alexandrov et al., 2012; Patz et al., 2013; Van Giau and An, 2016) because CSF is a clear biological fluid produced in the choroid plexus of the brain that circulates via the inner ventricular system, crosses the $\mathrm{BBB}$, and is absorbed into the bloodstream. The levels of target candidate miRNAs such as miR-9, miR-146a, and miR-155 were shown to be greatly increased in CSF from $\mathrm{AD}$ patients compared with those in age-matched controls, as quantified by microarrays and qRT-PCR (Alexandrov et al., 2012; Lukiw et al., 2012). Currently, urine is collected and analyzed for biomarker discovery and diagnostic purposes in clinical practice (Weber et al., 2010; Bryant et al., 2012). Exosomes can be purified from the urine using various methods such as differential ultracentrifugation (Alvarez et al., 2012), which is highly valuable for investigating whether miRNAs can be detected in the urine. However, it remains difficult to determine whether the alteration in miRNA levels in humans is a cause or consequence of the neurodegenerative process. Investigation of miRNA analysis profiles in AD animal models might help to solve this problem. Additionally, the potential to test miRNAs in biological body fluids may contribute to developing and promoting the discovery of specific biomarkers for neurodegenerative diseases such as AD.

\section{DEVELOPMENT OF A BRAIN-DERIVED EXOSOMAL BIOMARKER FOR AD}

Currently, a mixed population of exosomes from various types of cells can be separated from biological fluids by multiple

TABLE 2 | The biomarker of different neural derived exosomes (NDEs).

\begin{tabular}{|c|c|c|}
\hline Exosomes isolated from different cell types & Biomarker & Function \\
\hline \multirow[t]{2}{*}{$\begin{array}{l}\text { Cortical neurons-derived exosomes; immature and } \\
\text { mature hippocampal neurons exosomes }\end{array}$} & $\begin{array}{l}\text { The GluR } 2 / 3 \text { subunits of glutamate } \\
\text { receptors }\end{array}$ & $\begin{array}{l}\text { Neuronal markers and play key roles in virtually all excitatory } \\
\text { neurotransmission in the brain Faure et al., } 2006 .\end{array}$ \\
\hline & L1 cell adhesion molecule (L1CAM) & $\begin{array}{l}\text { Neuronal markers, cell adhesion molecule with an important role in } \\
\text { the development of the nervous system Lachenal et al., } 2011 .\end{array}$ \\
\hline Microglia-derived exosomes & $\begin{array}{l}\text { lonized calcium binding adaptor } \\
\text { molecule } 1 \text { (lba1) }\end{array}$ & $\begin{array}{l}\text { A microglia/macrophage-specific calcium-binding protein with } \\
\text { actin-bundling activity that participates in membrane ruffling and } \\
\text { phagocytosis in activated microglia Raffo-Romero et al., } 2018 .\end{array}$ \\
\hline \multirow[t]{3}{*}{ Astrocytic-derived exosomes } & $\begin{array}{l}\text { Glutamine aspartate transporter } \\
\text { (GLAST) }\end{array}$ & $\begin{array}{l}\text { Selective markers of astrocytic plasma membranes Raffo-Romero } \\
\text { et al., } 2018 .\end{array}$ \\
\hline & Glial fibrillary acidic protein (GFAP) & $\begin{array}{l}\text { A specific marker for astrocytes; the astrocytic cytoskeleton Goetzl } \\
\text { et al., 2016b. }\end{array}$ \\
\hline & Glutamine synthetase (GS) & $\begin{array}{l}\text { Astrocyte marker, it catalyzes the production of glutamine and } \\
\text { 4-aminobutanoate Goetzl et al., 2016b. }\end{array}$ \\
\hline \multirow[t]{2}{*}{ Oligodendrocytes-derived exosomes } & Myelin proteolipid protein (PLP) & $\begin{array}{l}\text { Oligodendrocytes marker, it is the major myelin protein from the } \\
\text { central nervous system. It plays an important role in the formation } \\
\text { or maintenance of the multilamellar structure of myelin } \\
\text { Kramer-Albers et al., } 2007 \text {. }\end{array}$ \\
\hline & $\begin{array}{l}2^{\prime}, 3^{\prime} \text {-cyclic nucleotide } \\
3^{\prime} \text {-phosphodiesterase (CNP) }\end{array}$ & $\begin{array}{l}\text { Oligodendrocytes marker, it belongs to the cyclic nucleotide } \\
\text { phosphodiesterase family Kramer-Albers et al., } 2007 .\end{array}$ \\
\hline
\end{tabular}




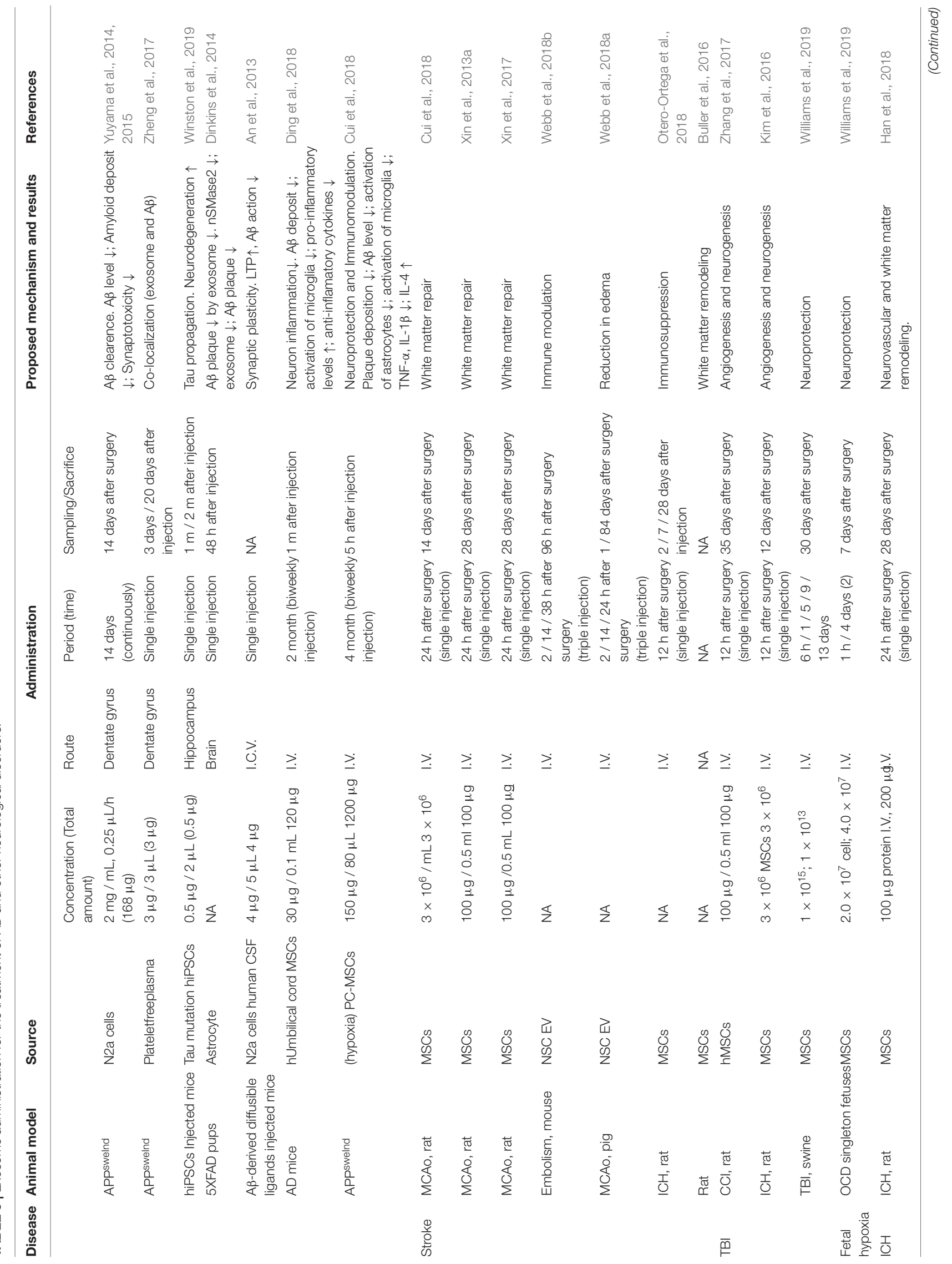




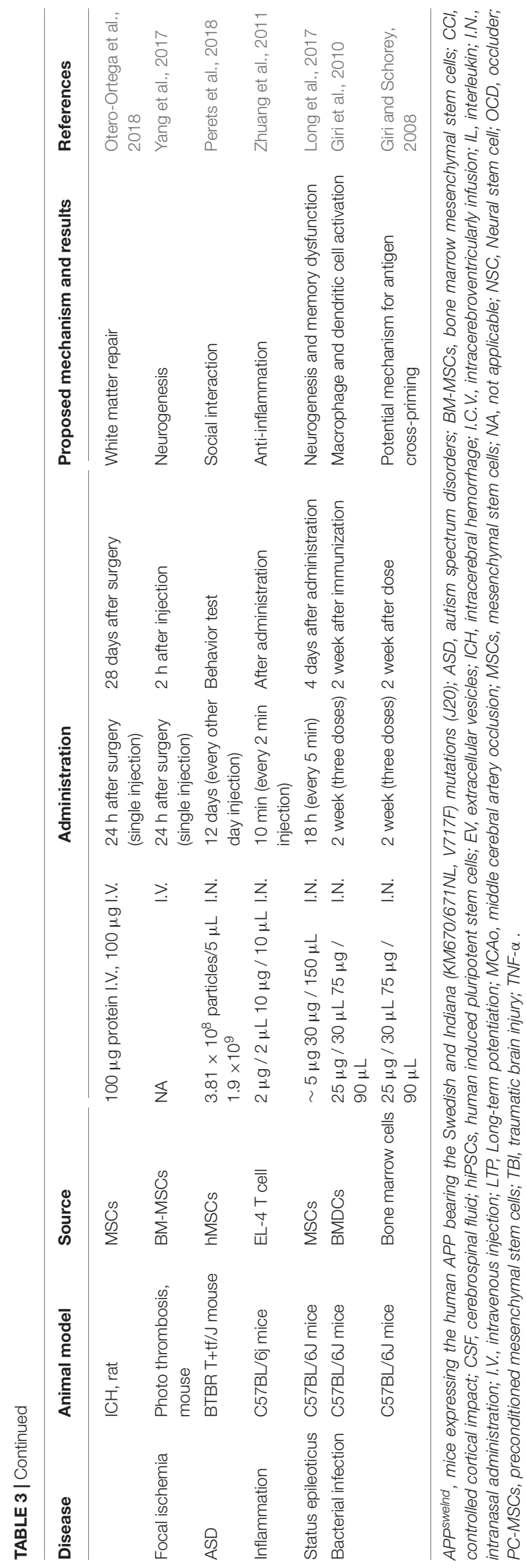

techniques such as classically differential ultracentrifugation, immunomagnetic beads and size exclusion chromatography (Li et al., 2017; Yu et al., 2018). Moreover, exosomes have a lipid bilayer to protect their cargo, which is used downstream, from RNAse treatment to be confirmed whether the miRNAs/mRNA analyzed are inside the exosomes or not (Cheng et al., 2014). This mixed population of exosomes may be recognized by western blots or mass spectrometry using proteins that are involved in the formation process of ILVs (Lotvall et al., 2014) as mentioned and discussed at the beginning of this manuscript. It is worth noting that many of these markers are not exclusive to exosomes and it is necessary to further examine the characteristics of exosomes (Watt et al., 2011). In the CNS, investigating cells from the brain may afford insights into the mechanisms of brain diseases (Saeedi et al., 2019). Isolating neuronal exosomes from cells related to AD may bridge the gaps in knowledge of peripheral biomarkers and provide mechanistic insight to this disease. Recently, a precipitation/immunoaffinity system has been developed to isolate neuron-derived and astrocyte-derived exosomes from the blood of AD patients (Goetzl et al., 2018). Data from these studies suggest that BDEs from blood plasma and measurement of certain forms of tau in BDEs can be used as diagnostic and prognostic biomarkers for $\mathrm{AD}$ (Guix et al., 2018; Saeedi et al., 2019).

Enrichment of a specific neuron-derived population of exosomes permits monitoring of target cells of interest (Table 2). Collectively, although exosome transfer of $A \beta$ seems to mainly occur in $\mathrm{AD}$ and can be exploited as a helpful biomarker of the disease course, development of additional exosome biomarkers could contribute to a more accurate diagnosis of $\mathrm{AD}$ and discovering further close connections between the marker and mechanisms of the early stage of $\mathrm{AD}$ as well as other neurodegenerative diseases.

\section{EXOSOMES AS NOVEL AD THERAPEUTICS}

The $\mathrm{BBB}$ is a continuous endothelial membrane within brain microvessels and is sheathed by mural vascular cells and perivascular astrocyte end-feet, which seal the cell-to-cell contacts to prevent the transmission of potentially toxic compounds between the brain and the blood (Matsumoto et al., 2017). In addition to transmembrane diffusion of small $(<400 \quad$ Da $)$ lipidsoluble molecules, the $\mathrm{BBB}$ permits selective transport of some compounds into and out of the brain (Sanchez-Covarrubias et al., 2014).

Exosomes have an inherent ability to cross the BBB, and because their properties remain active in the brain, they are ideal drug delivery vehicles. This BBB-penetrating capacity, which was first reported by Alvarez-Erviti et al. (2011), resulted in effective delivery of small-molecule drugs to the brain through systemic injection of naked exosomes in mice, leading to promotion of drug-mediated biological responses (Zhuang et al., 2011). Later studies have been successful in transmitting 
exosomes through intranasal injection into the mouse brain (Aliotta et al., 2007). Recently, a study using rats identified that the fluorescently tagged forebrain astrocyte protein aldolase C was selectively expressed in brain tissue and could be recovered in exosomes in the blood (Ratajczak et al., 2006; Gomez-Molina et al., 2019). This study affords evidence of communication mediated by exosomes from the brain to the rest of the body (Ratajczak et al., 2006; Gomez-Molina et al., 2019). Evidence from these studies illustrates that exosomes can cross the BBB in a bi-directional manner; however, their method of accurately crossing the BBB remains unclear and requires further study.

In contrast, while exosomes may play a role in the spreading of $\mathrm{AD}$, some studies have shown a positive effect of introducing non-pathogenic exosomes to change disease duration and progression (Table 3). In animal studies, this therapeutic effect was found when exosomes from young mice were observed to significantly downregulate aging-associated signaling molecules such as IGF1R and upregulate telomeraserelated genes such as Men1, Mre11a, Tep1, Terf2, Tert, and Tnks in aged mice (Lee et al., 2018). Furthermore, exosomes injected into the brain of transgenic mouse models of $\mathrm{AD}$ can help to decrease toxic oligomers and fibrils in a microglial-dependent manner following intracerebral administration, contributing to the clearance of $\mathrm{A} \beta$ in vivo (Yuyama et al., 2012, 2014; Yuyama and Igarashi, 2017). Other researchers have suggested that mesenchymal stromal-derived exosomes may have a therapeutic effect in vivo on the advancement of neurovascular plasticity in other neurodegenerative diseases such as stroke (Xin et al., 2013a).

Additionally, directed exosomal transmission systems for precision nanomedicine have attracted extensive interest across the fields of pharmaceutical sciences, molecular cell biology and nanoengineering (Zhu et al., 2018). Exosomes are also a promising type of novel drug delivery vehicle because of their ability to cross the BBB and shield their cargo from enzymatic and chemical degradation. Recent developments regarding nanoengineering using targeted exosomes for therapeutic purposes have been conducted by researchers, for example, Xin et al. (2013b), Tran et al. (2019).

Introducing exogenous exosomes into the CNS because they can effectively cross the BBB is a potentially novel strategy for $\mathrm{AD}$ therapies (Chen et al., 2016), and their innate secretion of enzymes could be beneficial for degrading toxic fibrils (Katsuda et al., 2015). The field of EV research is still at the initial stage in the CNS and yet improved therapeutic applications are already being developed.

\section{OPPORTUNITIES AND CHALLENGES}

Quantifying changes in EV cargo would be extremely difficult because of the lack of unique region-specific markers for circulating exosomes and the inaccessibility of specific brain tissue EVs from living patients. Interesting lines of research have examined both the induction of $\mathrm{AD}$ using pathogenic EVs and the sequestration of toxic plaques using exogenous healthy EVs.
It difficult to distinguish among EV types simply on the basis of protein markers or size alone. To better interpret and replicate the experimental results of exosome studies, combined exosome isolation methods as well as improved techniques for accurate purification and characterization are recommended. In addition, a crowdsourcing knowledgebase currently allows researchers in the EV field to track the latest EV biology and methodology (Lee et al., 2019).

In recent years, research has been focused on BDEs to attempt to solve questions of brain-associated disorders using blood biopsies. Exosomes isolated from plasma were used to enrich BDEs (Sun et al., 2017; Saeedi et al., 2019). This study demonstrated that both the number of neural-derived exosomes as well as the expression of $\mathrm{A} \beta$, neurofilament light chain, and high-mobility group box 1 potentially act as biomarkers of neuropsychological impairment in HIV (Sun et al., 2017). BDEs from plasma have also been tested in a pilot study to examine protein biomarkers for patients with major depressive disorder (Kuwano et al., 2018). Moreover, in military personal with mild traumatic brain injuries, compared with controls, the levels of tau, $\mathrm{A} \beta 42$, and IL-10 deposited by BDEs were elevated (Kuwano et al., 2018). Cargo proteins and miRNA from astrocytic-derived exosomes have been analyzed to obtain mechanistic insight into AD (Goetzl et al., 2016b). Additionally, other cell-derived exosomes have also been researched for other brain-related disorders. The ability to access BDEs in plasma and other biological body fluids such as CSF and urine shows potential for clinical use in treating nervous system disorders.

\section{CONCLUSION}

Although the domain of exosome investigation, especially BDEs, remains relatively novel, attractive evidence from other fields demonstrates that investigation of exosomes can afford insight into the disease mechanisms and processes associated with $\mathrm{AD}$ and treatment responses. Currently, increased research on exosomes has focused on biomarkers of the course of $\mathrm{AD}$ and their ability to mediate cell-to-cell communication in the nervous system. However, additional work is needed with respect to the mechanisms of bi-directional transport of cargo-carrying exosomes across the $\mathrm{BBB}$, the alterations in the number or size of exosomes secreted, changes in cargo constituents, and identification of differences in specific cell types. Meantime, it is necessary to take into consideration that several preparations may contain another type of EVs given the procedure used to obtain them. Exosomes derived from cells in the CNS have tremendous biomarker potential because they may reverse physiological changes in nervous system disorders, and these changes can be tested in the periphery.

\section{AUTHOR CONTRIBUTIONS}

$\mathrm{CQ}$ and ZS designed the project. ZS, YX, WD, LZ, $\mathrm{HZ}, \mathrm{YH}, \mathrm{PY}, \mathrm{YQ}$, and WZ performed a majority of 
writing the manuscript. All authors reviewed and revised the manuscript.

\section{FUNDING}

This work was supported by grants from the National Natural Science Foundation of China (Grant No. 81901114); the Fundamental Research Funds for the Central Universities (Grant No. 3332019091); and CAMS Innovation Fund for Medical

\section{REFERENCES}

Abdulrahman, B. A., Abdelaziz, D. H., and Schatzl, H. M. (2018). Autophagy regulates exosomal release of prions in neuronal cells. J. Biol. Chem. 293, 8956-8968. doi: 10.1074/jbc.RA117.000713

Abner, E. L., Jicha, G. A., Shaw, L. M., Trojanowski, J. Q., and Goetzl, E. J. (2016). Plasma neuronal exosomal levels of Alzheimer's disease biomarkers in normal aging. Ann. Clin. Transl. Neurol. 3, 399-403. doi: 10.1002/acn3.309

Aguirre, V., Werner, E. D., Giraud, J., Lee, Y. H., Shoelson, S. E., and White, M. F. (2002). Phosphorylation of Ser307 in insulin receptor substrate-1 blocks interactions with the insulin receptor and inhibits insulin action. J. Biol. Chem. 277, 1531-1537. doi: 10.1074/jbc.M101521200

Alexandrov, P. N., Dua, P., Hill, J. M., Bhattacharjee, S., Zhao, Y., and Lukiw, W. J. (2012). microRNA (miRNA) speciation in Alzheimer's disease (AD) cerebrospinal fluid (CSF) and extracellular fluid (ECF). Int. J. Biochem. Mol. Biol. 3, 365-373.

Aliotta, J. M., Sanchez-Guijo, F. M., Dooner, G. J., Johnson, K. W., Dooner, M. S., Greer, K. A., et al. (2007). Alteration of marrow cell gene expression, protein production, and engraftment into lung by lung-derived microvesicles: a novel mechanism for phenotype modulation. Stem Cells 25, 2245-2256. doi: 10.1634/ stemcells.2007-0128

Alvarez, M. L., Khosroheidari, M., Kanchi, R. R., and DiStefano, J. K. (2012). Comparison of protein, microRNA, and mRNA yields using different methods of urinary exosome isolation for the discovery of kidney disease biomarkers. Kidney Int. 82, 1024-1032. doi: 10.1038/ki.2012.256

Alvarez-Erviti, L., Seow, Y., Yin, H., Betts, C., Lakhal, S., and Wood, M. J. (2011). Delivery of siRNA to the mouse brain by systemic injection of targeted exosomes. Nat. Biotechnol. 29, 341-345. doi: 10.1038/nbt.1807

An, K., Klyubin, I., Kim, Y., Jung, J. H., Mably, A. J., O’Dowd, S. T., et al. (2013). Exosomes neutralize synaptic-plasticity-disrupting activity of $\mathrm{A} \beta$ assemblies in vivo. Mol:Brain 6, 47. doi: 10.1186/1756-6606-6-47

Asai, H., Ikezu, S., Tsunoda, S., Medalla, M., Luebke, J., Haydar, T., et al. (2015). Depletion of microglia and inhibition of exosome synthesis halt tau propagation. Nat. Neurosci. 18, 1584-1593. doi: 10.1038/nn.4132

Atienzar-Aroca, S., Flores-Bellver, M., Serrano-Heras, G., Martinez-Gil, N., Barcia, J. M., Aparicio, S., et al. (2016). Oxidative stress in retinal pigment epithelium cells increases exosome secretion and promotes angiogenesis in endothelial cells. J. Cell. Mol. Med. 20, 1457-1466. doi: 10.1111/jcmm.12834

Bahrini, I., Song, J. H., Diez, D., and Hanayama, R. (2015). Neuronal exosomes facilitate synaptic pruning by up-regulating complement factors in microglia. Sci. Rep. 5:7989. doi: 10.1038/srep07989

Baker, S., Polanco, J. C., and Gotz, J. (2016). Extracellular vesicles containing P301L mutant tau accelerate pathological tau phosphorylation and oligomer formation but do not seed mature neurofibrillary tangles in ALZ17 mice. J. Alzheimers Dis. 54, 1207-1217. doi: 10.3233/JAD-160371

Bellingham, S. A., Guo, B. B., Coleman, B. M., and Hill, A. F. (2012). Exosomes: vehicles for the transfer of toxic proteins associated with neurodegenerative diseases? Front. Physiol. 3:124. doi: 10.3389/fphys.2012.00124

Bianco, F., Pravettoni, E., Colombo, A., Schenk, U., Möller, T., Matteoli, M., et al. (2005). Astrocyte-Derived ATP induces vesicle shedding and IL-1 $\beta$ release from microglia. J. Immunol. 174:7268. doi: 10.4049/jimmunol.174.11.7268

Bolmont, T., Haiss, F., Eicke, D., Radde, R., Mathis, C. A., Klunk, W. E., et al. (2008). Dynamics of the microglial/amyloid interaction indicate a role in plaque maintenance. J. Neurosci. 28:4283. doi: 10.1523/JNEUROSCI.4814-07.2008
Sciences (Grant Nos. 2019-I2M-1-003 and 2016-12M-2-006); and Young Elite Scientists Sponsorship Program by CAST (YESS) (Grant No. 2019QNRC001).

\section{ACKNOWLEDGMENTS}

ZS wishes to extend her deepest appreciation and thanks to her husband, Mr. Xing Le, who has always supported her career and research.

Brunkhorst, R., Vutukuri, R., and Pfeilschifter, W. (2014). Fingolimod for the treatment of neurological diseases-state of play and future perspectives. Front. Cell. Neurosci. 8:283. doi: 10.3389/fncel.2014.00283

Bryant, R. J., Pawlowski, T., Catto, J. W., Marsden, G., Vessella, R. L., Rhees, B., et al. (2012). Changes in circulating microRNA levels associated with prostate cancer. Br. J. Cancer 106, 768-774. doi: 10.1038/bjc.2011.595

Buller, B., Moore, T., Zhang, Y., Pikula, E., Martin, C., Mortazavi, F., et al. (2016). Exosomes from rhesus monkey MSCs promote neuronal growth and myelination. Stroke 47:A68.

Burgos, K., Malenica, I., Metpally, R., Courtright, A., Rakela, B., Beach, T., et al. (2014). Profiles of extracellular miRNA in cerebrospinal fluid and serum from patients with Alzheimer's and Parkinson's diseases correlate with disease status and features of pathology. PLoS One 9:e94839. doi: 10.1371/journal.pone. 0094839

Camussi, G., Deregibus, M. C., Bruno, S., Grange, C., Fonsato, V., and Tetta, C. (2011). Exosome/microvesicle-mediated epigenetic reprogramming of cells. Am. J. Cancer Res. 1, 98-110.

Chen, C. C., Liu, L., Ma, F., Wong, C. W., Guo, X. E., Chacko, J. V., et al. (2016). Elucidation of exosome migration across the blood-brain barrier model in vitro. Cell. Mol. Bioeng. 9, 509-529. doi: 10.1007/s12195-0160458-3

Cheng, L., Sharples, R. A., Scicluna, B. J., and Hill, A. F. (2014). Exosomes provide a protective and enriched source of miRNA for biomarker profiling compared to intracellular and cell-free blood. J. Extracell Vesicles 3:23743. doi: 10.3402/jev. v3.23743

Chen-Plotkin, A. S., Unger, T. L., Gallagher, M. D., Bill, E., Kwong, L. K., VolpicelliDaley, L., et al. (2012). TMEM106B, the risk gene for frontotemporal dementia, is regulated by the microRNA-132/212 cluster and affects progranulin pathways. J. Neurosci. 32, 11213-11227. doi: 10.1523/JNEUROSCI.0521-12. 2012

Chesser, A. S., Pritchard, S. M., and Johnson, G. V. (2013). Tau clearance mechanisms and their possible role in the pathogenesis of Alzheimer disease. Front. Neurol. 4:122. doi: 10.3389/fneur.2013.00122

Chiasserini, D., van Weering, J. R., Piersma, S. R., Pham, T. V., Malekzadeh, A., Teunissen, C. E., et al. (2014). Proteomic analysis of cerebrospinal fluid extracellular vesicles: a comprehensive dataset. J. Proteomics 106, 191-204. doi: 10.1016/j.jprot.2014.04.028

Chivet, M., Hemming, F., Pernet-Gallay, K., Fraboulet, S., and Sadoul, R. (2012). Emerging role of neuronal exosomes in the central nervous system. Front. Physiol. 3:145. doi: 10.3389/fphys.2012.00145

Chow, V. W., Mattson, M. P., Wong, P. C., and Gleichmann, M. (2010). An Overview of APP Processing Enzymes and Products. Neuromol. Med. 12, 1-12. doi: 10.1007/s12017-009-8104-z

Cicognola, C., Brinkmalm, G., Wahlgren, J., Portelius, E., Gobom, J., Cullen, N. C., et al. (2019). Novel tau fragments in cerebrospinal fluid: relation to tangle pathology and cognitive decline in Alzheimer's disease. Acta Neuropathol. 137, 279-296. doi: 10.1007/s00401-018-1948-2

Cogswell, J. P., Ward, J., Taylor, I. A., Waters, M., Shi, Y., Cannon, B., et al. (2008). Identification of miRNA changes in Alzheimer's disease brain and CSF yields putative biomarkers and insights into disease pathways. J. Alzheimers Dis. 14, 27-41. doi: 10.3233/jad-2008-14103

Cohen, M., Appleby, B., and Safar, J. G. (2016). Distinct prion-like strains of amyloid beta implicated in phenotypic diversity of Alzheimer's disease. Prion 10,9-17. doi: 10.1080/19336896.2015.1123371 
Colombo, M., Raposo, G., and Thery, C. (2014). Biogenesis, secretion, and intercellular interactions of exosomes and other extracellular vesicles. Annu. Rev. Cell Dev. Biol. 30, 255-289. doi: 10.1146/annurev-cellbio-101512-122326

Corrado, C., Raimondo, S., Chiesi, A., Ciccia, F., De Leo, G., and Alessandro, R. (2013). Exosomes as intercellular signaling organelles involved in health and disease: basic science and clinical applications. Int. J. Mol. Sci. 14, 5338-5366. doi: 10.3390/ijms14035338

Crotti, A., Sait, H. R., McAvoy, K. M., Estrada, K., Ergun, A., Szak, S., et al. (2019). BIN1 favors the spreading of Tau via extracellular vesicles. Sci. Rep. 9:9477. doi: 10.1038/s41598-019-45676-0

Cui, G., Wu, J., Mou, F., Xie, W., Wang, F., Wang, Q., et al. (2018). Exosomes derived from hypoxia-preconditioned mesenchymal stromal cells ameliorate cognitive decline by rescuing synaptic dysfunction and regulating inflammatory responses in APP/PS1 mice. FASEB J. 32, 654-668. doi: 10.1096/fj.201700600R

Czubowicz, K., Jesko, H., Wencel, P., Lukiw, W. J., and Strosznajder, R. P. (2019). The role of ceramide and sphingosine-1-phosphate in Alzheimer's disease and other neurodegenerative disorders. Mol. Neurobiol. 56, 5436-5455. doi: 10. 1007/s12035-018-1448-3

de la Monte, S. M. (2009). Insulin resistance and Alzheimer's disease. BMB Rep. 42, 475-481. doi: 10.5483/bmbrep.2009.42.8.475

de la Monte, S. M., and Tong, M. (2014). Brain metabolic dysfunction at the core of Alzheimer's disease. Biochem. Pharmacol. 88, 548-559. doi: 10.1016/j.bcp.2013. 12.012

Del, C. I., Shrimpton, C. N., Thiagarajan, P., and Lopez, J. A. (2005). Tissue-factorbearing microvesicles arise from lipid rafts and fuse with activated platelets to initiate coagulation. Blood 106, 1604-1611. doi: 10.1182/blood-2004-03-1095

DeLeo, A. M., and Ikezu, T. (2018). Extracellular vesicle biology in Alzheimer's disease and related tauopathy. J. Neuroimmune Pharmacol. 13, 292-308. doi: 10.1007/s11481-017-9768-z

Devi, L., and Anandatheerthavarada, H. K. (2010). Mitochondrial trafficking of APP and alpha synuclein: relevance to mitochondrial dysfunction in Alzheimer's and Parkinson's diseases. Biochim. Biophys. Acta 1802, 11-19. doi: 10.1016/j.bbadis.2009.07.007

Ding, M., Shen, Y., Wang, P., Xie, Z., Xu, S., Zhu, Z., et al. (2018). Exosomes Isolated From Human Umbilical cord mesenchymal stem cells alleviate neuroinflammation and reduce amyloid-beta deposition by modulating microglial activation in Alzheimer's Disease. Neurochem. Res. 43, 2165-2177. doi: 10.1007/s11064-018-2641-5

Dinkins, M. B., Dasgupta, S., Wang, G., Zhu, G., and Bieberich, E. (2014). Exosome reduction in vivo is associated with lower amyloid plaque load in the 5XFAD mouse model of Alzheimer's disease. Neurobiol. Aging 35, 1792-1800. doi: 10.1016/j.neurobiolaging.2014.02.012

Dinkins, M. B., Wang, G., and Bieberich, E. (2017). Sphingolipid-enriched extracellular vesicles and Alzheimer's disease: a decade of research. J. Alzheimers Dis. 60, 757-768. doi: 10.3233/JAD- 160567

Drago, F., Lombardi, M., Prada, I., Gabrielli, M., Joshi, P., Cojoc, D., et al. (2017). ATP modifies the proteome of extracellular vesicles released by microglia and influences their action on astrocytes. Front. Pharmacol. 8:910. doi: 10.3389/ fphar.2017.00910

Draznin, B. (2006). Molecular mechanisms of insulin resistance: serine phosphorylation of insulin receptor substrate-1 and increased expression of p85alpha: the two sides of a coin. Diabetes 55, 2392-2397. doi: 10.2337/db060391

Eitan, E., Hutchison, E. R., Marosi, K., Comotto, J., Mustapic, M., Nigam, S. M., et al. (2016a). Extracellular vesicle-associated $A \beta$ mediates trans-neuronal bioenergetic and $\mathrm{Ca}$ 2+-handling deficits in Alzheimer's disease models. NPJ Aging Mech. Dis. 2:16019. doi: 10.1038/npjamd.2016.19

Eitan, E., Suire, C., Zhang, S., and Mattson, M. P. (2016b). Impact of lysosome status on extracellular vesicle content and release. Ageing Res. Rev. 32, 65-74. doi: 10.1016/j.arr.2016.05.001

Emmanouilidou, E., Melachroinou, K., Roumeliotis, T., Garbis, S. D., Ntzouni, M., Margaritis, L. H., et al. (2010). Cell-produced alpha-synuclein is secreted in a calcium-dependent manner by exosomes and impacts neuronal survival. J. Neurosci. 30, 6838-6851. doi: 10.1523/JNEUROSCI.5699-09. 2010

Faure, J., Lachenal, G., Court, M., Hirrlinger, J., Chatellard-Causse, C., Blot, B., et al. (2006). Exosomes are released by cultured cortical neurones. Mol. Cell. Neurosci. 31, 642-648. doi: 10.1016/j.mcn.2005.12.003
Fevrier, B., Vilette, D., Archer, F., Loew, D., Faigle, W., Vidal, M., et al. (2004). Cells release prions in association with exosomes. Proc. Natl. Acad. Sci. U.S.A. 101, 9683-9688. doi: 10.1073/pnas.0308413101

Fiandaca, M. S., Kapogiannis, D., Mapstone, M., Boxer, A., Eitan, E., Schwartz, J. B., et al. (2015). Identification of preclinical Alzheimer's disease by a profile of pathogenic proteins in neurally derived blood exosomes: a case-control study. Alzheimers Dement. 11,600-607.e1. doi: 10.1016/j.jalz.2014.06.008

Fruhbeis, C., Frohlich, D., Kuo, W. P., Amphornrat, J., Thilemann, S., Saab, A. S., et al. (2013a). Neurotransmitter-triggered transfer of exosomes mediates oligodendrocyte-neuron communication. PLoS Biol. 11:e1001604. doi: 10.1371/ journal.pbio.1001604

Fruhbeis, C., Frohlich, D., Kuo, W. P., and Kramer-Albers, E. M. (2013b). Extracellular vesicles as mediators of neuron-glia communication. Front. Cell. Neurosci. 7:182. doi: 10.3389/fncel.2013.00182

Gatti, S., Bruno, S., Deregibus, M. C., Sordi, A., Cantaluppi, V., Tetta, C., et al. (2011). Microvesicles derived from human adult mesenchymal stem cells protect against ischaemia-reperfusion-induced acute and chronic kidney injury. Nephrol. Dial Transplant. 26, 1474-1483. doi: 10.1093/ndt/gfr015

Geekiyanage, H., Jicha, G. A., Nelson, P. T., and Chan, C. (2012). Blood serum miRNA: non-invasive biomarkers for Alzheimer's disease. Exp. Neurol. 235, 491-496. doi: 10.1016/j.expneurol.2011.11.026

Gill, J., Mustapic, M., Diaz-Arrastia, R., Lange, R., Gulyani, S., Diehl, T., et al. (2018). Higher exosomal tau, amyloid-beta 42 and IL-10 are associated with mild TBIs and chronic symptoms in military personnel. Brain Inj. 32, $1277-$ 1284. doi: 10.1080/02699052.2018.1471738

Gimbel, D. A., Nygaard, H. B., Coffey, E. E., Gunther, E. C., Lauren, J., Gimbel, Z. A., et al. (2010). Memory impairment in transgenic Alzheimer mice requires cellular prion protein. J. Neurosci. 30, 6367-6374. doi: 10.1523/JNEUROSCI. 0395- 10.2010

Giri, P. K., Kruh, N. A., Dobos, K. M., and Schorey, J. S. (2010). Proteomic analysis identifies highly antigenic proteins in exosomes from $M$. tuberculosis-infected and culture filtrate protein-treated macrophages. Proteomics 10, 3190-3202. doi: 10.1002/pmic.200900840

Giri, P. K., and Schorey, J. S. (2008). Exosomes derived from M. Bovis BCG infected macrophages activate antigen-specific CD4+ and CD8+ T cells in vitro and in vivo. PLoS One 3:e2461. doi: 10.1371/journal.pone.0002461

Goetzl, E. J., Abner, E. L., Jicha, G. A., Kapogiannis, D., and Schwartz, J. B. (2018). Declining levels of functionally specialized synaptic proteins in plasma neuronal exosomes with progression of Alzheimer's disease. FASEB J. 32, 888-893. doi: 10.1096/fj.201700731R

Goetzl, E. J., Boxer, A., Schwartz, J. B., Abner, E. L., Petersen, R. C., Miller, B. L., et al. (2015). Low neural exosomal levels of cellular survival factors in Alzheimer's disease. Ann. Clin. Transl. Neurol. 2, 769-773. doi: 10.1002/ac n3.211

Goetzl, E. J., Kapogiannis, D., Schwartz, J. B., Lobach, I. V., Goetzl, L., Abner, E. L., et al. (2016a). Decreased synaptic proteins in neuronal exosomes of frontotemporal dementia and Alzheimer's disease. FASEB J. 30, 4141-4148. doi: 10.1096/fj.201600816R

Goetzl, E. J., Mustapic, M., Kapogiannis, D., Eitan, E., Lobach, I. V., Goetzl, L., et al. (2016b). Cargo proteins of plasma astrocyte-derived exosomes in Alzheimer's disease. FASEB J. 30, 3853-3859. doi: 10.1096/fj.201600756R

Goetzl, E. J., Nogueras-Ortiz, C., Mustapic, M., Mullins, R. J., Abner, E. L., Schwartz, J. B., et al. (2019). Deficient neurotrophic factors of CSPG4-type neural cell exosomes in Alzheimer disease. FASEB J. 33, 231-238. doi: 10.1096/ fj. 201801001

Gomez-Molina, C., Sandoval, M., Henzi, R., Ramirez, J. P., Varas-Godoy, M., Luarte, A., et al. (2019). Small extracellular vesicles in rat serum contain astrocyte-derived protein biomarkers of repetitive stress. Int. J. Neuropsychopharmacol. 22, 232-246. doi: 10.1093/ijnp/pyy098

Guitart, K., Loers, G., Buck, F., Bork, U., Schachner, M., and Kleene, R. (2016). Improvement of neuronal cell survival by astrocyte-derived exosomes under hypoxic and ischemic conditions depends on prion protein. Glia 64, 896-910. doi: 10.1002/glia.22963

Guix, F. X., Corbett, G. T., Cha, D. J., Mustapic, M., Liu, W., and Mengel, D., et al. (2018). Detection of aggregation-competent tau in neuron-derived extracellular vesicles. Int. J. Mol. Sci. 19:663. doi: 10.3390/ijms19030663

Hamlett, E. D., Goetzl, E. J., Ledreux, A., Vasilevko, V., Boger, H. A., LaRosa, A., et al. (2017). Neuronal exosomes reveal Alzheimer's disease biomarkers 
in Down syndrome. Alzheimers Dement. 13, 541-549. doi: 10.1016/j.jalz.2016. 08.012

Hamlett, E. D., Ledreux, A., Potter, H., Chial, H. J., Patterson, D., Espinosa, J. M., et al. (2018). Exosomal biomarkers in Down syndrome and Alzheimer's disease. Free Radic. Bio. Med. 114, 110-121. doi: 10.1016/j.freeradbiomed.2017.08.028

Han, Y., Seyfried, D., Meng, Y., Yang, D., Schultz, L., Chopp, M., et al. (2018). Multipotent mesenchymal stromal cell-derived exosomes improve functional recovery after experimental intracerebral hemorrhage in the rat. J. Neurosurg. 131, 290-300. doi: 10.3171/2018.2.JNS171475

Hartmann, A., Muth, C., Dabrowski, O., Krasemann, S., and Glatzel, M. (2017). Exosomes and the prion protein: more than one truth. Front. Neurosci. 11:194. doi: 10.3389/fnins.2017.00194

Hebert, S. S., Wang, W. X., Zhu, Q., and Nelson, P. T. (2013). A study of small RNAs from cerebral neocortex of pathology-verified Alzheimer's disease, dementia with lewy bodies, hippocampal sclerosis, frontotemporal lobar dementia, and non-demented human controls. J. Alzheimers Dis. 35, 335-348. doi: 10.3233/ JAD- 122350

Heijnen, H. F., Schiel, A. E., Fijnheer, R., Geuze, H. J., and Sixma, J. J. (1999). Activated platelets release two types of membrane vesicles: microvesicles by surface shedding and exosomes derived from exocytosis of multivesicular bodies and alpha-granules. Blood 94, 3791-3799.

Heisler, F. F., Pechmann, Y., Wieser, I., Altmeppen, H. C., Veenendaal, L., Muhia, M., et al. (2018). Muskelin coordinates PrPC lysosome versus exosome targeting and impacts prion disease progression. Neuron 99, 1155.-1169. doi: 10.1016/j. neuron.2018.08.010

Hickman, S. E., Allison, E. K., and El Khoury, J. (2008). Microglial dysfunction and defective $\beta$-amyloid clearance pathways in aging alzheimer\&\#039; s disease mice. J. Neurosci. 28:8354. doi: 10.1523/JNEUROSCI.0616-08.2008

Huang, T., Liu, Y., Huang, M., Zhao, X., and Cheng, L. (2010). Wnt1-cremediated conditional loss of Dicer results in malformation of the midbrain and cerebellum and failure of neural crest and dopaminergic differentiation in mice. J. Mol. Cell Biol. 2, 152-163. doi: 10.1093/jmcb/mjq008

Hurley, J. H. (2010). The ESCRT complexes. Crit. Rev. Biochem. Mol. Biol. 45, 463-487. doi: 10.3109/10409238.2010.502516

Iraci, N., Leonardi, T., Gessler, F., Vega, B., and Pluchino, S. (2016). Focus on extracellular vesicles: physiological role and signalling properties of extracellular membrane vesicles. Int. J. Mol. Sci. 17:171. doi: 10.3390/ ijms17020171

Jahn, R., and Fasshauer, D. (2012). Molecular machines governing exocytosis of synaptic vesicles. Nature 490, 201-207. doi: 10.1038/nature11320

Johnson, G. V., and Stoothoff, W. H. (2004). Tau phosphorylation in neuronal cell function and dysfunction. J. Cell Sci. 117, 5721-5729. doi: 10.1242/jcs.01558

Johnson, R., Zuccato, C., Belyaev, N. D., Guest, D. J., Cattaneo, E., and Buckley, N. J. (2008). A microRNA-based gene dysregulation pathway in Huntington's disease. Neurobiol. Dis. 29, 438-445. doi: 10.1016/j.nbd.2007.11.001

Johnstone, R. M., Adam, M., Hammond, J. R., Orr, L., and Turbide, C. (1987). Vesicle formation during reticulocyte maturation. Association of plasma membrane activities with released vesicles (exosomes). J. Biol. Chem. 262, 9412-9420.

Kajimoto, T., Mohamed, N., Badawy, S., Matovelo, S. A., Hirase, M., Nakamura, S., et al. (2018). Involvement of Gbetagamma subunits of Gi protein coupled with S1P receptor on multivesicular endosomes in F-actin formation and cargo sorting into exosomes. J. Biol. Chem. 293, 245-253. doi: 10.1074/jbc.M117. 808733

Kalluri, R., and LeBleu, V. S. (2020). The biology, function, and biomedical applications of exosomes. Science 367:eaau6977. doi: 10.1126/science.aau6977

Kapitein, L. C., and Hoogenraad, C. C. (2015). Building the Neuronal Microtubule Cytoskeleton. Neuron 87, 492-506. doi: 10.1016/j.neuron.2015.05.046

Kapogiannis, D., Boxer, A., Schwartz, J. B., Abner, E. L., Biragyn, A., Masharani, U., et al. (2015). Dysfunctionally phosphorylated type 1 insulin receptor substrate in neural-derived blood exosomes of preclinical Alzheimer's disease. FASEB J. 29, 589-596. doi: 10.1096/fj.14-262048

Katsuda, T., Oki, K., and Ochiya, T. (2015). Potential application of extracellular vesicles of human adipose tissue-derived mesenchymal stem cells in Alzheimer's disease therapeutics. Methods Mol. Biol. 1212, 171-181. doi: 10.1007/7651_ 2014_98

Kawase Koga, Y., Otaegi, G., and Sun, T. (2009). Different timings of Dicer deletion affect neurogenesis and gliogenesis in the developing mouse central nervous system. Dev. Dyn. 238, 2800-2812. doi: 10.1002/dvdy. 22109

Kellett, K. A., and Hooper, N. M. (2009). Prion protein and Alzheimer disease. Prion 3, 190-194. doi: 10.4161/pri.3.4.9980

Kim, A. H., Reimers, M., Maher, B., Williamson, V., McMichael, O., McClay, J. L., et al. (2010). MicroRNA expression profiling in the prefrontal cortex of individuals affected with schizophrenia and bipolar disorders. Schizophr. Res. 124, 183-191. doi: 10.1016/j.schres.2010.07.002

Kim, B., Figueroa-Romero, C., Pacut, C., Backus, C., and Feldman, E. L. (2015). Insulin resistance prevents AMPK-induced Tau dephosphorylation through Akt-mediated Increase in AMPKSer-485 phosphorylation. J. Biol. Chem. 290, 19146-19157. doi: 10.1074/jbc.M115.636852

Kim, D., Nishida, H., An, S. Y., Shetty, A. K., Bartosh, T. J., and Prockop, D. J. (2016). Chromatographically isolated CD63+ CD81+ extracellular vesicles from mesenchymal stromal cells rescue cognitive impairments after TBI. Proc. Natl. Acad. Sci. U.S.A. 113, 170-175. doi: 10.1073/pnas.1522297113

King, H. W., Michael, M. Z., and Gleadle, J. M. (2012). Hypoxic enhancement of exosome release by breast cancer cells. BMC Cancer 12:421. doi: 10.1186/14712407-12-421

Klumperman, J., and Raposo, G. (2014). The complex ultrastructure of the endolysosomal system. Cold Spring Harb. Perspect. Biol. 6:a016857. doi: 10. 1101/cshperspect.a016857

Koniusz, S., Andrzejewska, A., Muraca, M., Srivastava, A. K., Janowski, M., and Lukomska, B. (2016). Extracellular vesicles in physiology, pathology, and therapy of the immune and central nervous system, with focus on extracellular vesicles derived from mesenchymal stem cells as therapeutic tools. Front. Cell. Neurosci. 10:109. doi: 10.3389/fncel.2016.00109

Kowal, J., Arras, G., Colombo, M., Jouve, M., Morath, J. P., PrimdalBengtson, B., et al. (2016). Proteomic comparison defines novel markers to characterize heterogeneous populations of extracellular vesicle subtypes. Proc. Natl. Acad. Sci. U.S.A. 113, E968-E977. doi: 10.1073/pnas.152123 0113

Kramer-Albers, E. M., Bretz, N., Tenzer, S., Winterstein, C., Mobius, W., Berger, H., et al. (2007). Oligodendrocytes secrete exosomes containing major myelin and stress-protective proteins: trophic support for axons? Proteomics Clin. Appl. 1, 1446-1461. doi: 10.1002/prca.200700522

Kuwano, N., Kato, T. A., Mitsuhashi, M., Sato-Kasai, M., Shimokawa, N., Hayakawa, K., et al. (2018). Neuron-related blood inflammatory markers as an objective evaluation tool for major depressive disorder: an exploratory pilot case-control study. J. Affect. Disord. 240, 88-98. doi: 10.1016/j.jad.2018. 07.040

Lachenal, G., Pernet-Gallay, K., Chivet, M., Hemming, F. J., Belly, A., Bodon, G., et al. (2011). Release of exosomes from differentiated neurons and its regulation by synaptic glutamatergic activity. Mol. Cell. Neurosci. 46, 409-418. doi: 10.1016/j.mcn.2010.11.004

Lai, R. C., Chen, T. S., and Lim, S. K. (2011). Mesenchymal stem cell exosome: a novel stem cell-based therapy for cardiovascular disease. Regen. Med. 6, 481-492. doi: 10.2217/rme.11.35

Lau, P., Frigerio, C. S., and De Strooper, B. (2014). Variance in the identification of microRNAs deregulated in Alzheimer's disease and possible role of lincRNAs in the pathology: the need of larger datasets. Ageing Res. Rev. 17, 43-53. doi: 10.1016/j.arr.2014.02.006

Laulagnier, K., Javalet, C., Hemming, F. J., Chivet, M., Lachenal, G., Blot, B., et al. (2018). Amyloid precursor protein products concentrate in a subset of exosomes specifically endocytosed by neurons. Cell. Mol. Life Sci. 75, 757-773. doi: 10.1007/s00018-017-2664-0

Lee, B. R., Kim, J. H., Choi, E. S., Cho, J. H., and Kim, E. (2018). Effect of young exosomes injected in aged mice. Int. J. Nanomed. 13, 5335-5345. doi: 10.2147/ IJN.S170680

Lee, S., Mankhong, S., and Kang, J. H. (2019). Extracellular vesicle as a source of Alzheimer's biomarkers: opportunities and challenges. Int. J. Mol. Sci. 20:E1728. doi: 10.3390/ijms20071728

Lee, Y., El, A. S., and Wood, M. J. (2012). Exosomes and microvesicles: extracellular vesicles for genetic information transfer and gene therapy. Hum. Mol. Genet. 21, R125-R134. doi: 10.1093/hmg/dds317

Lehmann, B. D., Paine, M. S., Brooks, A. M., McCubrey, J. A., Renegar, R. H., Wang, R., et al. (2008). Senescence-associated exosome release from human prostate cancer cells. Cancer Res. 68, 7864-7871. doi: 10.1158/0008-5472.CAN-07-6538 
Li, P., Kaslan, M., Lee, S. H., Yao, J., and Gao, Z. (2017). Progress in exosome isolation techniques. Theranostics 7, 789-804. doi: 10.7150/thno.18133

Liu, W., Bai, X., Zhang, A., Huang, J., Xu, S., and Zhang, J. (2019). Role of exosomes in central nervous system diseases. Front. Mol. Neurosci. 12:240. doi: 10.3389/fnmol.2019.00240

Long, Q., Upadhya, D., Hattiangady, B., Kim, D., An, S. Y., Shuai, B., et al. (2017). Intranasal MSC-derived A1-exosomes ease inflammation, and prevent abnormal neurogenesis and memory dysfunction after status epilepticus. Proc. Natl. Acad. Sci. U.S.A. 114, E3536-E3545. doi: 10.1073/pnas.1703920114

Lotvall, J., Hill, A. F., Hochberg, F., Buzas, E. I., Di Vizio, D., Gardiner, C., et al. (2014). Minimal experimental requirements for definition of extracellular vesicles and their functions: a position statement from the International Society for Extracellular Vesicles. J. Extracell Vesicles 3:26913. doi: 10.3402/jev.v3. 26913

Luarte, A., Henzi, R., Fernández, A., Gaete, D., Cisternas, P., Pizarro, M., et al. (2020). Astrocyte-derived small extracellular vesicles regulate dendritic complexity through miR-26a-5p Activity. Cells 9:930. doi: 10.3390/cells9040930

Lucey, B. P., McCullough, A., Landsness, E. C., Toedebusch, C. D., McLeland, J. S., Zaza, A. M., et al. (2019). Reduced non-rapid eye movement sleep is associated with tau pathology in early Alzheimer's disease. Sci. Transl. Med. 11:eaau6550. doi: 10.1126/scitranslmed.aau6550

Lukiw, W. J., Alexandrov, P. N., Zhao, Y., Hill, J. M., and Bhattacharjee, S. (2012). Spreading of Alzheimer's disease inflammatory signaling through soluble micro-RNA. Neuroreport 23, 621-626. doi: 10.1097/WNR.0b013e32835542b0

Malla, R. R., Pandrangi, S., Kumari, S., Gavara, M. M., and Badana, A. K. (2018). Exosomal tetraspanins as regulators of cancer progression and metastasis and novel diagnostic markers. Asia Pac. J. Clin. Oncol. 14, 383-391. doi: 10.1111/ ajco.12869

Martin, L., Latypova, X., and Terro, F. (2011). Post-translational modifications of tau protein: implications for Alzheimer's disease. Neurochem. Int. 58, 458-471. doi: 10.1016/j.neuint.2010.12.023

Matsumoto, J., Stewart, T., Sheng, L., Li, N., Bullock, K., Song, N., et al. (2017). Transmission of alpha-synuclein-containing erythrocyte-derived extracellular vesicles across the blood-brain barrier via adsorptive mediated transcytosis: another mechanism for initiation and progression of Parkinson's disease? Acta Neuropathol. Commun. 5:71. doi: 10.1186/s40478-017-0470-4

McKelvey, K. J., Powell, K. L., Ashton, A. W., Morris, J. M., and McCracken, S. A. (2015). Exosomes: mechanisms of uptake. J. Circ. Biomark 4:7. doi: 10.5772/ 61186

Men, Y., Yelick, J., Jin, S., Tian, Y., Chiang, M., Higashimori, H., et al. (2019). Exosome reporter mice reveal the involvement of exosomes in mediating neuron to astroglia communication in the CNS. Nat. Commun. 10:4136. doi: 10.1038/s41467-019-11534-w

Miranda, A. M., Lasiecka, Z. M., Xu, Y., Neufeld, J., Shahriar, S., Simoes, S., et al. (2018). Neuronal lysosomal dysfunction releases exosomes harboring APP C-terminal fragments and unique lipid signatures. Nat. Commun. 9:291. doi: 10.1038/s41467-017-02533-w

Momen-Heravi, F., Saha, B., Kodys, K., Catalano, D., Satishchandran, A., and Szabo, G. (2015). Increased number of circulating exosomes and their microRNA cargos are potential novel biomarkers in alcoholic hepatitis. J. Transl. Med. 13:261. doi: 10.1186/s12967-015-0623-9

Morel, L., Regan, M., Higashimori, H., Ng, S. K., Esau, C., Vidensky, S., et al. (2013). Neuronal exosomal miRNA-dependent translational regulation of astroglial glutamate transporter GLT1. J. Biol. Chem. 288, 7105-7116. doi: 10.1074/jbc. M112.410944

Morris, G. P., Clark, I. A., Zinn, R., and Vissel, B. (2013). Microglia: a new frontier for synaptic plasticity, learning and memory, and neurodegenerative disease research. Neurobiol. Learn. Mem. 105, 40-53. doi: 10.1016/j.nlm.2013.07.002

Mulcahy, L. A., Pink, R. C., and Carter, D. R. (2014). Routes and mechanisms of extracellular vesicle uptake. J. Extracell Vesicles 3:24641. doi: 10.3402/jev.v3. 24641

Mullins, R. J., Mustapic, M., Goetzl, E. J., and Kapogiannis, D. (2017). Exosomal biomarkers of brain insulin resistance associated with regional atrophy in Alzheimer's disease. Hum. Brain Mapp. 38, 1933-1940. doi: 10.1002/hbm.23494

Ngolab, J., Trinh, I., Rockenstein, E., Mante, M., Florio, J., Trejo, M., et al. (2017). Brain-derived exosomes from dementia with Lewy bodies propagate alphasynuclein pathology. Acta Neuropathol. Commun. 5:46. doi: 10.1186/s40478017-0445-5
Ophelders, D. R., Wolfs, T. G., Jellema, R. K., Zwanenburg, A., Andriessen, P., Delhaas, T., et al. (2016). Mesenchymal stromal cell-derived extracellular vesicles protect the fetal brain after hypoxia-ischemia. Stem Cell. Transl. Med. 5, 754-763. doi: 10.5966/sctm.2015-0197

Otero-Ortega, L., Gómez De Frutos, M. C., Laso-García, F., Rodríguez-Frutos, B., Medina-Gutiérrez, E., Lopez, J. A., et al. (2018). Exosomes promote restoration after an experimental animal model of intracerebral hemorrhage. J. Cereb. Blood Flow Metab. 38, 767-779. doi: 10.1177/0271678X17708917

Packer, A. N., Xing, Y., Harper, S. Q., Jones, L., and Davidson, B. L. (2008). The bifunctional microRNA miR-9/miR-9* regulates REST and CoREST and is downregulated in Huntington's disease. J. Neurosci. 28, 14341-14346. doi: 10.1523/JNEUROSCI.2390-08.2008

Pan, B. T., and Johnstone, R. M. (1983). Fate of the transferrin receptor during maturation of sheep reticulocytes in vitro: selective externalization of the receptor. Cell 33, 967-978. doi: 10.1016/0092-8674(83)90040-5

Pascua-Maestro, R., González, E., Lillo, C., Ganfornina, M. D., Falcón-Pérez, J. M., and Sanchez, D. (2019). Extracellular vesicles secreted by astroglial cells transport Apolipoprotein D to neurons and mediate neuronal survival upon oxidative stress. Front. Cell. Neurosci. 12:526. doi: 10.3389/fncel.2018.00526

Patz, S., Trattnig, C., Grunbacher, G., Ebner, B., Gully, C., Novak, A., et al. (2013). More than cell dust: microparticles isolated from cerebrospinal fluid of brain injured patients are messengers carrying mRNAs, miRNAs, and proteins. J. Neurotrauma 30, 1232-1242. doi: 10.1089/neu.2012.2596

Perets, N., Hertz, S., London, M., and Offen, D. (2018). Intranasal administration of exosomes derived from mesenchymal stem cells ameliorates autistic-like behaviors of BTBR mice. Mol. Autism 9:57. doi: 10.1186/s13229-018-0240-6

Perez, M., Avila, J., and Hernandez, F. (2019). Propagation of Tau via Extracellular Vesicles. Front. Neurosci. 13:698. doi: 10.3389/fnins.2019.00698

Perkins, D. O., Jeffries, C. D., Jarskog, L. F., Thomson, J. M., Woods, K., Newman, M. A., et al. (2007). microRNA expression in the prefrontal cortex of individuals with schizophrenia and schizoaffective disorder. Genome Biol. 8:R27. doi: 10. 1186/gb-2007-8-2-r27

Polanco, J. C., Scicluna, B. J., Hill, A. F., and Gotz, J. (2016). Extracellular vesicles isolated from the brains of $\mathrm{rTg} 4510$ mice seed Tau protein aggregation in a threshold-dependent manner. J. Biol. Chem. 291, 12445-12466. doi: 10.1074/ jbc.M115.709485

Prusiner, S. B. (1982). Novel proteinaceous infectious particles cause scrapie. Science 216, 136-144. doi: 10.1126/science.6801762

Puglielli, L., Ellis, B. C., Saunders, A. J., and Kovacs, D. M. (2003). Ceramide stabilizes beta-site amyloid precursor protein-cleaving enzyme 1 and promotes amyloid beta-peptide biogenesis. J. Biol. Chem. 278, 19777-19783. doi: 10.1074/ jbc.M300466200

Raffo-Romero, A., Arab, T., Al-Amri, I. S., Le Marrec-Croq, F., Van Camp, C., Lemaire, Q., et al. (2018). Medicinal leech CNS as a model for exosome studies in the crosstalk between microglia and neurons. Int. J. Mol. Sci. 19:E4124. doi: 10.3390/ijms19124124

Rajendran, L., Bali, J., Barr, M. M., Court, F. A., Kramer-Albers, E. M., Picou, F., et al. (2014). Emerging roles of extracellular vesicles in the nervous system. J. Neurosci. 34, 15482-15489. doi: 10.1523/JNEUROSCI.3258-14.2014

Rajendran, L., Honsho, M., Zahn, T. R., Keller, P., Geiger, K. D., Verkade, P., et al. (2006). Alzheimer's disease beta-amyloid peptides are released in association with exosomes. Proc. Natl. Acad. Sci. U.S.A. 103, 11172-11177. doi: 10.1073/ pnas.0603838103

Rak, J., and Guha, A. (2012). Extracellular vesicles-vehicles that spread cancer genes. Bioessays 34, 489-497. doi: 10.1002/bies.201100169

Ratajczak, J., Miekus, K., Kucia, M., Zhang, J., Reca, R., Dvorak, P., et al. (2006). Embryonic stem cell-derived microvesicles reprogram hematopoietic progenitors: evidence for horizontal transfer of mRNA and protein delivery. Leukemia 20, 847-856. doi: 10.1038/sj.leu.2404132

Saeedi, S., Israel, S., Nagy, C., and Turecki, G. (2019). The emerging role of exosomes in mental disorders. Transl. Psychiatry 9:122. doi: 10.1038/s41398019-0459-9

Saman, S., Kim, W., Raya, M., Visnick, Y., Miro, S., Saman, S., et al. (2012). Exosome-associated tau is secreted in tauopathy models and is selectively phosphorylated in cerebrospinal fluid in early Alzheimer disease. J. Biol. Chem. 287, 3842-3849. doi: 10.1074/jbc.M111.277061

Saman, S., Lee, N. C., Inoyo, I., Jin, J., Li, Z., Doyle, T., et al. (2014). Proteins recruited to exosomes by tau overexpression implicate novel cellular 
mechanisms linking tau secretion with Alzheimer's disease. J. Alzheimers Dis. 40, S47-S70. doi: 10.3233/JAD-132135

Sanchez-Covarrubias, L., Slosky, L. M., Thompson, B. J., Davis, T. P., and Ronaldson, P. T. (2014). Transporters at CNS barrier sites: obstacles or opportunities for drug delivery? Curr. Pharm. Des. 20, 1422-1449. doi: 10.2174/ 13816128113199990463

Santa-Maria, I., Alaniz, M. E., Renwick, N., Cela, C., Fulga, T. A., Van Vactor, D., et al. (2015). Dysregulation of microRNA-219 promotes neurodegeneration through post-transcriptional regulation of tau. J. Clin. Invest. 125, 681-686. doi: 10.1172/JCI78421

Sardar, S. M., Ansell-Schultz, A., Civitelli, L., Hildesjo, C., Larsson, M., Lannfelt, L., et al. (2018). Alzheimer's disease pathology propagation by exosomes containing toxic amyloid-beta oligomers. Acta Neuropathol. 136, 41-56.

Sarkar, S., Jun, S., Rellick, S., Quintana, D. D., Cavendish, J. Z., and Simpkins, J. W. (2016). Expression of microRNA-34a in Alzheimer's disease brain targets genes linked to synaptic plasticity, energy metabolism, and resting state network activity. Brain Res. 1646, 139-151. doi: 10.1016/j.brainres.2016.05.026

Sawamura, N., Ko, M., Yu, W., Zou, K., Hanada, K., Suzuki, T., et al. (2004). Modulation of amyloid precursor protein cleavage by cellular sphingolipids. J. Biol. Chem. 279, 11984-11991. doi: 10.1074/jbc.M309832200

Saxton, R. A., and Sabatini, D. M. (2017). mTOR signaling in growth, metabolism, and disease. Cell 169, 361-371. doi: 10.1016/j.cell.2017.03.035

Sempere, L. F., Freemantle, S., Pitha-Rowe, I., Moss, E., Dmitrovsky, E., and Ambros, V. (2004). Expression profiling of mammalian microRNAs uncovers a subset of brain-expressed microRNAs with possible roles in murine and human neuronal differentiation. Genome Biol. 5:R13. doi: 10.1186/gb-2004-5-3-r13

Sethi, P., and Lukiw, W. J. (2009). Micro-RNA abundance and stability in human brain: specific alterations in Alzheimer's disease temporal lobe neocortex. Neurosci. Lett. 459, 100-104. doi: 10.1016/j.neulet.2009.04.052

Sharma, P., Schiapparelli, L., and Cline, H. T. (2013). Exosomes function in cellcell communication during brain circuit development. Curr. Opin. Neurobiol. 23, 997-1004. doi: 10.1016/j.conb.2013.08.005

Sharples, R. A., Vella, L. J., Nisbet, R. M., Naylor, R., Perez, K., Barnham, K. J., et al. (2008). Inhibition of $\gamma$-secretase causes increased secretion of amyloid precursor protein C-terminal fragments in association with exosomes. FASEB J. 22, 1469-1478. doi: 10.1096/fj.07-9357com

Sheinerman, K. S., Tsivinsky, V. G., Crawford, F., Mullan, M. J., Abdullah, L., and Umansky, S. R. (2012). Plasma microRNA biomarkers for detection of mild cognitive impairment. Aging (Albany NY) 4, 590-605. doi: 10.18632/aging. 100486

Sinha, M. S., Ansell-Schultz, A., Civitelli, L., Hildesjö, C., Larsson, M., Lannfelt, L., et al. (2018). Alzheimer's disease pathology propagation by exosomes containing toxic amyloid-beta oligomers. Acta Neuropathol. 136, 41-56. doi: 10.1007/s00401-018-1868-1

Skog, J., Wurdinger, T., van Rijn, S., Meijer, D. H., Gainche, L., Sena-Esteves, M., et al. (2008). Glioblastoma microvesicles transport RNA and proteins that promote tumour growth and provide diagnostic biomarkers. Nat. Cell Biol. 10, 1470-1476. doi: 10.1038/ncb1800

Song, Z., Zhao, D., and Yang, L. (2013). Molecular mechanisms of neurodegeneration mediated by dysfunctional subcellular organelles in transmissible spongiform encephalopathies. Acta Biochim. Biophys. Sin. (Shanghai) 45, 452-464. doi: 10.1093/abbs/gmt014

Sotiropoulos, I., Galas, M. C., Silva, J. M., Skoulakis, E., Wegmann, S., Maina, M. B., et al. (2017). Atypical, non-standard functions of the microtubule associated Tau protein. Acta Neuropathol. Commun. 5:91. doi: 10.1186/s40478-0170489-6

Stuffers, S., Sem, W. C., Stenmark, H., and Brech, A. (2009). Multivesicular endosome biogenesis in the absence of ESCRTs. Traffic 10, 925-937. doi: 10. 1111/j.1600-0854.2009.00920.x

Sun, B., Dalvi, P., Abadjian, L., Tang, N., and Pulliam, L. (2017). Blood neuronderived exosomes as biomarkers of cognitive impairment in HIV. AIDS 31, F9-F17. doi: 10.1097/QAD.0000000000001595

Takeda, S. (2019). Progression of Alzheimer's disease, tau propagation, and its modifiable risk factors. Neurosci. Res. 141, 36-42. doi: 10.1016/j.neures.2018. 08.005

Thompson, A. G., Gray, E., Heman-Ackah, S. M., Mager, I., Talbot, K., Andaloussi, S. E., et al. (2016). Extracellular vesicles in neurodegenerative disease - pathogenesis to biomarkers. Nat. Rev. Neurol. 12, 346-357. doi: 10.1038/ nrneurol.2016.68

Timmers, L., Lim, S. K., Hoefer, I. E., Arslan, F., Lai, R. C., van Oorschot, A. A., et al. (2011). Human mesenchymal stem cell-conditioned medium improves cardiac function following myocardial infarction. Stem Cell Res. 6, 206-214. doi: 10.1016/j.scr.2011.01.001

Trajkovic, K., Hsu, C., Chiantia, S., Rajendran, L., Wenzel, D., Wieland, F., et al. (2008). Ceramide triggers budding of exosome vesicles into multivesicular endosomes. Science 319, 1244-1247. doi: 10.1126/science.115 3124

Tran, P., Xiang, D., Tran, T., Yin, W., Zhang, Y., Kong, L., et al. (2019). Exosomes and nanoengineering: a match made for precision therapeutics. Adv. Mater. 18:e1904040. doi: 10.1002/adma.201904040

Trotta, T., Panaro, M. A., Cianciulli, A., Mori, G., Di Benedetto, A., and Porro, C. (2018). Microglia-derived extracellular vesicles in Alzheimer's Disease: a double-edged sword. Biochem. Pharmacol. 148, 184-192. doi: 10.1016/j.bcp. 2017.12.020

Urbanelli, L., Magini, A., Buratta, S., Brozzi, A., Sagini, K., Polchi, A., et al. (2013). Signaling pathways in exosomes biogenesis, secretion and fate. Genes (Basel) 4, 152-170. doi: 10.3390/genes4020152

Valadi, H., Ekstrom, K., Bossios, A., Sjostrand, M., Lee, J. J., and Lotvall, J. O. (2007). Exosome-mediated transfer of mRNAs and microRNAs is a novel mechanism of genetic exchange between cells. Nat. Cell Biol. 9, 654-659. doi: 10.1038/ncb 1596

van der Pol, E., Boing, A. N., Harrison, P., Sturk, A., and Nieuwland, R. (2012). Classification, functions, and clinical relevance of extracellular vesicles. Pharmacol. Rev. 64, 676-705. doi: 10.1124/pr.112.005983

Van Giau, V., and An, S. S. (2016). Emergence of exosomal miRNAs as a diagnostic biomarker for Alzheimer's disease. J. Neurol. Sci. 360, 141-152. doi: 10.1016/j. jns.2015.12.005

van Niel, G., Charrin, S., Simoes, S., Romao, M., Rochin, L., Saftig, P., et al. (2011). The tetraspanin CD63 regulates ESCRT-independent and -dependent endosomal sorting during melanogenesis. Dev. Cell 21, 708-721. doi: 10.1016/j. devcel.2011.08.019

van Niel, G., D'Angelo, G., and Raposo, G. (2018). Shedding light on the cell biology of extracellular vesicles. Nat. Rev. Mol. Cell Biol. 19, 213-228. doi: 10.1038/nrm.2017.125

van Niel, G., Porto-Carreiro, I., Simoes, S., and Raposo, G. (2006). Exosomes: a common pathway for a specialized function. J. Biochem. 140, 13-21. doi: $10.1093 / \mathrm{jb} / \mathrm{mvj} 128$

Villemagne, V. L., Burnham, S., Bourgeat, P., Brown, B., Ellis, K. A., Salvado, O., et al. (2013). Amyloid beta deposition, neurodegeneration, and cognitive decline in sporadic Alzheimer's disease: a prospective cohort study. Lancet Neurol. 12, 357-367. doi: 10.1016/S1474-4422(13)70044-9

Wang, G., Dinkins, M., He, Q., Zhu, G., Poirier, C., Campbell, A., et al. (2012). Astrocytes secrete exosomes enriched with proapoptotic ceramide and prostate apoptosis response 4 (PAR-4) potential mechanism of apoptosis induction in Alzheimer disease (AD). J. Biol. Chem. 287, 21384-21395. doi: 10.1074/jbc. M112.340513

Wang, Y., Balaji, V., Kaniyappan, S., Kruger, L., Irsen, S., Tepper, K., et al. (2017). The release and trans-synaptic transmission of Tau via exosomes. Mol. Neurodegener. 12:5. doi: 10.1186/s13024-016-0143-y

Watson, L. S., Hamlett, E. D., Stone, T. D., and Sims-Robinson, C. (2019). Neuronally derived extracellular vesicles: an emerging tool for understanding Alzheimer's disease. Mol. Neurodegener. 14:22. doi: 10.1186/s13024-0190317-5

Watt, A. D., Perez, K. A., Faux, N. G., Pike, K. E., Rowe, C. C., Bourgeat, P., et al. (2011). Increasing the predictive accuracy of amyloid-beta blood-borne biomarkers in Alzheimer's disease. J. Alzheimers Dis. 24, 47-59. doi: 10.3233/ JAD-2010-101722

Webb, R. L., Kaiser, E. E., Jurgielewicz, B. J., Spellicy, S., Scoville, S. L., Thompson, T. A., et al. (2018a). Human neural stem cell extracellular vesicles improve recovery in a porcine model of ischemic stroke. Stroke 49, 1248-1256. doi: 10.1161/STROKEAHA.117.020353

Webb, R. L., Kaiser, E. E., Scoville, S. L., Thompson, T. A., Fatima, S., Pandya, C., et al. (2018b). Human neural stem cell extracellular vesicles improve tissue and functional recovery in the murine thromboembolic 
stroke model. Transl. Stroke Res. 9, 530-539. doi: 10.1007/s12975-0170599-2

Weber, J. A., Baxter, D. H., Zhang, S., Huang, D. Y., Huang, K. H., Lee, M. J., et al. (2010). The microRNA spectrum in 12 body fluids. Clin. Chem. 56, 1733-1741. doi: 10.1373/clinchem.2010.147405

Williams, A. M., Dennahy, I. S., Bhatti, U. F., Halaweish, I., Xiong, Y., Chang, P., et al. (2019). Mesenchymal stem cell-derived exosomes provide neuroprotection and improve long-term neurologic outcomes in a swine model of traumatic brain injury and hemorrhagic shock. J. Neurotraum. 36, 54-60. doi: 10.1089/neu.2018.5711

Winston, C. N., Aulston, B., Rockenstein, E. M., Adame, A., Prikhodko, O., Dave, K. N., et al. (2019). Neuronal exosome-derived human tau is toxic to recipient mouse neurons in vivo. J. Alzheimers Dis. 67, 541-553. doi: 10.3233/JAD180776

Winston, C. N., Goetzl, E. J., Akers, J. C., Carter, B. S., Rockenstein, E. M., Galasko, D., et al. (2016). Prediction of conversion from mild cognitive impairment to dementia with neuronally derived blood exosome protein profile. Alzheimers Dement. 3, 63-72. doi: 10.1016/j.dadm.2016.04.001

Wong, H. K., Veremeyko, T., Patel, N., Lemere, C. A., Walsh, D. M., Esau, C., et al. (2013). De-repression of FOXO3a death axis by microRNA-132 and -212 causes neuronal apoptosis in Alzheimer's disease. Hum. Mol. Genet. 22, 3077-3092. doi: 10.1093/hmg/ddt164

Xiao, T., Zhang, W., Jiao, B., Pan, C., Liu, X., and Shen, L. (2017). The role of exosomes in the pathogenesis of Alzheimer'disease. Transl. Neurodegener. 6:3. doi: 10.1186/s40035-017-0072-X

Xiao, X., Yu, S., Li, S., Wu, J., Ma, R., Cao, H., et al. (2014). Exosomes: decreased sensitivity of lung cancer A549 cells to cisplatin. PLoS One 9:e89534. doi: 10. 1371/journal.pone.0089534

Xin, H., Katakowski, M., Wang, F., Qian, J., Liu, X. S., Ali, M. M., et al. (2017). MicroRNA-17-92 cluster in exosomes enhance neuroplasticity and functional recovery after stroke in rats. Stroke 48, 747-753. doi: 10.1161/STROKEAHA. 116.015204

Xin, H., Li, Y., Cui, Y., Yang, J. J., Zhang, Z. G., and Chopp, M. (2013a). Systemic administration of exosomes released from mesenchymal stromal cells promote functional recovery and neurovascular plasticity after stroke in rats. J. Cereb. Blood Flow Metab. 33, 1711-1715. doi: 10.1038/jcbfm.2013.152

Xin, H., Li, Y., Liu, Z., Wang, X., Shang, X., Cui, Y., et al. (2013b). MiR-133b promotes neural plasticity and functional recovery after treatment of stroke with multipotent mesenchymal stromal cells in rats via transfer of exosome-enriched extracellular particles. Stem Cells 31, 2737-2746. doi: 10. 1002/stem.1409

Yamada, K., Cirrito, J. R., Stewart, F. R., Jiang, H., Finn, M. B., Holmes, B. B., et al. (2011). In vivo microdialysis reveals age-dependent decrease of brain interstitial fluid tau levels in P301S human tau transgenic mice. J. Neurosci. 31, 13110-13117. doi: 10.1523/JNEUROSCI.2569-11.2011

Yang, J., Zhang, X., Chen, X., Wang, L., and Yang, G. (2017). Exosome mediated delivery of miR-124 promotes neurogenesis after ischemia. Mol. Ther. Nucleic Acids 7, 278-287. doi: 10.1016/j.omtn.2017.04.010

Yokoi, A., Villar-Prados, A., Oliphint, P. A., Zhang, J., Song, X., De Hoff, P., et al. (2019). Mechanisms of nuclear content loading to exosomes. Sci. Adv. 5:eaax8849. doi: 10.1126/sciadv.aax8849
You, Y., and Ikezu, T. (2019). Emerging roles of extracellular vesicles in neurodegenerative disorders. Neurobiol. Dis. 130:104512. doi: 10.1016/j.nbd. 2019.104512

Yu, L. L., Zhu, J., Liu, J. X., Jiang, F., Ni, W. K., Qu, L. S., et al. (2018). A comparison of traditional and novel methods for the separation of exosomes from human samples. Biomed. Res. Int. 2018:3634563. doi: 10.1155/2018/363 4563

Yuyama, K., and Igarashi, Y. (2017). Exosomes as carriers of Alzheimer's amyloidss. Front. Neurosci. 11:229. doi: 10.3389/fnins.2017.00229

Yuyama, K., Sun, H., Mitsutake, S., and Igarashi, Y. (2012). Sphingolipidmodulated exosome secretion promotes clearance of amyloid- $\beta$ by microglia. J. Biol. Chem. 287, 10977-10989. doi: 10.1074/jbc.M111.324616

Yuyama, K., Sun, H., Sakai, S., Mitsutake, S., Okada, M., Tahara, H., et al. (2014). Decreased amyloid- $\beta$ pathologies by intracerebral loading of glycosphingolipidenriched exosomes in Alzheimer model mice. J. Biol. Chem. 289, 24488-24498. doi: 10.1074/jbc.M114.577213

Yuyama, K., Sun, H., Usuki, S., Sakai, S., Hanamatsu, H., Mioka, T., et al. (2015). A potential function for neuronal exosomes: sequestering intracerebral amyloid- $\beta$ peptide. FEBS Lett. 589, 84-88. doi: 10.1016/j.febslet.2014.11.027

Zhang, Y., Chopp, M., Zhang, Z. G., Katakowski, M., Xin, H., Qu, C., et al. (2017). Systemic administration of cell-free exosomes generated by human bone marrow derived mesenchymal stem cells cultured under 2D and 3D conditions improves functional recovery in rats after traumatic brain injury. Neurochem. Int. 111, 69-81. doi: 10.1016/j.neuint.2016.08.003

Zheng, T., Pu, J., Chen, Y., Mao, Y., Guo, Z., Pan, H., et al. (2017). Plasma exosomes spread and cluster around $\beta$-amyloid plaques in an animal model of Alzheimer's disease. Front. Aging Neurosci. 9:12. doi: 10.3389/fnagi.2017. 00012

Zhu, Q., Heon, M., Zhao, Z., and He, M. (2018). Microfluidic engineering of exosomes: editing cellular messages for precision therapeutics. Lab. Chip. 18, 1690-1703. doi: 10.1039/c8lc00246k

Zhuang, X., Xiang, X., Grizzle, W., Sun, D., Zhang, S., Axtell, R. C., et al. (2011). Treatment of brain inflammatory diseases by delivering exosome encapsulated anti-inflammatory drugs from the nasal region to the brain. Mol. Ther. 19, 1769-1779. doi: 10.1038/mt.2011.164

Zitvogel, L., Regnault, A., Lozier, A., Wolfers, J., Flament, C., Tenza, D., et al. (1998). Eradication of established murine tumors using a novel cell-free vaccine: dendritic cell-derived exosomes. Nat. Med. 4, 594-600. doi: 10.1038/nm0598594

Conflict of Interest: The authors declare that the research was conducted in the absence of any commercial or financial relationships that could be construed as a potential conflict of interest.

Copyright (c) 2020 Song, Xu, Deng, Zhang, Zhu, Yu, Qu, Zhao, Han and Qin. This is an open-access article distributed under the terms of the Creative Commons Attribution License (CC BY). The use, distribution or reproduction in other forums is permitted, provided the original author(s) and the copyright owner(s) are credited and that the original publication in this journal is cited, in accordance with accepted academic practice. No use, distribution or reproduction is permitted which does not comply with these terms. 